\title{
AS CLASS ACTIONS E AS ÚLTIMAS MUDANÇAS NA REGRA 23 DO ESTATUTO PROCESSUAL FEDERAL NORTE-AMERICANO ${ }^{1}$
}

\section{CLASS ACTIONS AND THE LAST CHANGES IN RULE 23 OF THE NORTH AMERICAN FEDERAL PROCEDURAL STATUTE}

\section{Aluisio Gonçalves de Castro Mendes}

Desembargador Federal. Presidente da $3^{\text {a }}$ Seção Especializada do Tribunal Regional Federal da $2^{\mathrm{a}}$ Região. Professor Titular de Direito Processual Civil da Universidade do Estado do Rio de Janeiro (UERJ) e do Programa de Pós-Graduação em Direito (PPGD) da Universidade Estácio de Sá (Unesa). Pós-Doutor pela Universidade de Regensburg, Alemanha. Doutor em Direito pela Universidade Federal do Paraná (UFPR), em doutorado cooperativo com a Johann Wolfgang Goethe Universität (Frankfurt am Main, Alemanha). Mestre em Direito pela Universidade Federal do Paraná (UFPR). Mestre em Direito pela Johann Wolfgang Goethe Universität (Frankfurt am Main, Alemanha). Especialista em Direito Processual Civil pela Universidade de Brasília (UnB). Graduado em Direito pela Universidade do Estado do Rio de Janeiro (UERJ) e em Comunicação Social pela Pontifícia Universidade Católica do Rio de Janeiro (PUC-RJ). Membro da Academia Brasileira de Letras Jurídicas (ABLJ). Diretor do Instituto Brasileiro de Direito Processual (IBDP) e do Instituto Ibero-americano de Direito Processual (IIDP). Membro da International Association of Procedural Law (IAPL). Membro do Grupo de Trabalho, do Conselho Nacional de Justiça (CNJ), encarregado da elaboração de propostas legislativas, judiciais e administrativas em prol das Ações Coletivas. Rio de Janeiro/RJ. E-mail: aluisiomendes@terra.com.br

\footnotetext{
${ }^{1}$ Artigo recebido em 18/12/2020, sob dispensa de revisão.
} 
Carolina Paes de Castro Mendes

Mestranda em Direito Processual pela Universidade do Estado do Rio de Janeiro. Graduada em Direito pela Pontifícia Universidade Católica do Rio de Janeiro (PUC-RJ). Advogada em Licks Advogados. Rio de Janeiro/RJ.

RESUMO. O presente artigo expõe e analisa as recentes reformas empreendidas na legislação federal norte-americana sobre class actions, que entraram em vigor em dezembro de 2018, na busca do aprimoramento do Direito Processual Coletivo, procurando extrair aspectos que possam ter relevância também para a tutela coletiva no panorama contemporâneo mundial e nacional, neste momento em que a Lei da Ação Civil Pública no Brasil completa 35 anos de existência.

PALAVRAS-ChAVE. Ações Coletivas. Tutela coletiva. Regra 23. Direito norteamericano. Reformas.

ABSTRACT. This paper exposes and analyzes the recent reforms undertaken in US federal legislation on class actions, which came into force in December 2018, in the pursuit of improving Collective Procedural Law, seeking to extract aspects that may also have relevance for collective redress in the contemporary world and national panorama, at this moment when the Law of Public Civil Action in Brazil completes 35 years of existence.

KEY WORDS. Class Actions. Collective Redress. Rule 23. North-American Law. Reforms.

\section{Notas Introdutórias}

Em tempos de pandemia, provocada pelo COVID-19, o fenômeno da globalização fica mais patente e evidente do que nunca. A internacionalização dos institutos jurídicos também vivencia esta realidade cada vez mais interligada. Nesse sentido, as ações coletivas encontram-se, nos dias de hoje, disseminadas, com os seus desafios, problemas, virtudes e 
dificuldades, pelo mundo inteiro. E, assim como na medicina, o estudo das experiências alienígenas é um imperativo importante, para que se possa cotejar as normas e os resultados, na busca do aprimoramento universal e nacional.

A troca de experiências é fundamental para que se possa avançar na construção de um sistema melhor. Isso é o que vem ocorrendo no cenário mundial, transpondo as barreiras e aproximando institutos das famílias de common e de civil law, como se pode facilmente constatar em dois fenômenos. Os países com tradição calcada no direito costumeiro passaram a usar muito mais o direito escrito, tanto legislando quanto mediante peças escritas, como os written statements, nos processos judiciais. Por sua vez, os países com origem no civil law, como o Brasil, vem adotando ou introduzindo elementos do sistema de stare decisis, fortalecendo o papel e o caráter vinculativo dos precedentes.

A origem histórica das ações coletivas está relacionada, mais remotamente, à ação popular, do direito romano, e às ações representativas, do direito inglês ${ }^{2}$. Contudo, nos últimos três séculos, o direito norte-americano desenvolveu bastante as denominadas ações de classe, passando a ter um caráter protagonista no cenário internacional. Passou a ser um referencial necessário nos estudos desenvolvidos ao redor do mundo, não obstante os problemas e as sucessivas modificações legislativas adotadas, para a correção dos problemas que passaram a ser apontados.

No presente texto, se fará uma exposição histórica do desenvolvimento do Direito Processual Coletivo nos Estados Unidos, com ênfase nas alterações legislativas que entraram em vigor em dezembro de 2018, para que possa, em seguida, efetuar a comparação com alguns aspectos da Lei da Ação Civil Pública, análise de elementos fundamentais e perspectivas para o aprimoramento da tutela coletiva no cenário mundial e nacional.

A Lei da Ação Civil Pública brasileira, em conjunto com o Código de Defesa do Consumidor, foram e continuam sendo, também, um referencial mundial, tendo servido de

\footnotetext{
2 Vide, nesse sentido: MENDES, Aluisio Gonçalves de Castro. Ações coletivas e meios de resolução coletiva de conflitos no direito comparado e nacional. $4^{\mathrm{a}}$. ed. São Paulo: Revista dos Tribunais, 2014.
} 
exemplo para vários países da América Latina ${ }^{3}$ e para a elaboração do próprio Código Modelo de Processos Coletivos para os países ibero-americanos ${ }^{4}$.

Passadas, contudo, três décadas da edição da LACP e do CDC, vem se mostrando necessária a reflexão sobre a necessidade de atualização da legislação brasileira sobre processos coletivos.

Essa diretriz foi percebida, inicialmente, pela academia, especialmente pelos Grupos de Pesquisa estruturados na Pós-Graduação da Faculdade de Direito da Universidade do Estado do Rio de Janeiro (UERJ) e da Universidade Estácio de Sá (UNESA) e na Universidade de São Paulo (USP), que, praticamente em concomitância, no Rio de Janeiro e em São Paulo, elaboraram um anteprojeto de Código Brasileiro de Processos Coletivos ${ }^{5}$, nos anos de 2004 a 2006.

No ano de 2008, foi constituída Comissão Especial de Juristas ${ }^{6}$, que elaborou um anteprojeto de Lei Geral dos Processos Coletivos, que foi incorporado ao II Pacto Republicano por um sistema de justiça mais acessível, ágil e eficiente, celebrado pelos chefes dos três Poderes, e encaminhado ao Congresso Nacional ${ }^{7}$, em abril de 2009, como Projeto de Lei 5.139/2009.

\footnotetext{
3 Vide: MENDES, Aluisio Gonçalves de Castro. Processos coletivos na Ibero-América. In: LUCON, Paulo Henrique dos Santos et alii. Processo em Jornadas: XI Jornadas Brasileiras de Direito Processual e XXV Jornadas Ibero-americanas de Direito Processual. Salvador: JusPodivm, 2016.

${ }^{4}$ MENDES, Aluisio Gonçalves de Castro. Ações coletivas e outros meios de resolução coletiva dos conflitos no direito comparado e nacional, p. 177 a 189.

5 Coordenados, respectivamente, por Aluisio Gonçalves de Castro Mendes e Ada Pellegrini Grinover. Vide GRINOVER, Ada Pellegrini; MENDES, Aluisio Gonçalves de Castro; WATANABE, Kazuo. Direito Processual Coletivo e o anteprojeto de Código Brasileiro de Processos Coletivos. São Paulo: Revista dos Tribunais, 2007.

${ }^{6}$ A Comissão Especial foi composta pelos seguintes membros: Rogério Favreto, Secretário da Reforma do Judiciário; Luiz Manoel Gomes Jr., Ada Pellegrini Grinover, Alexandre Lipp João, Aluisio Gonçalves de Castro Mendes, André da Silva Ordacgy, Anizio Pires Gavião Filho, Antonio Augusto de Aras, Antonio Carlos Oliveira Gidi, Athos Gusmão Carneiro, Consuelo Yatsuda Moromizato Yoshida, Elton Venturi, Fernando da Fonseca Gajardoni, Gregório Assagra de Almeida, Haman Tabosa de Moraes e Córdova, João Ricardo dos Santos Costa, José Adonis Callou de Araújo Sá, José Augusto Garcia de Souza, Luiz Philippe Vieira de Mello Filho, Luiz Rodrigues Wambier, Petrônio Calmon Filho, Ricardo de Barros Leonel, Ricardo Pippi Schmidt e Sérgio Cruz Arenhart; além de representantes da Casa Civil da Presidência da República, da Advocacia Geral da União, do Ministério da Fazenda e das Secretarias de Assuntos Legislativos, Direito Econômico e Consultoria Jurídica do Ministério da Justiça. Foi escolhida, ainda, uma Comissão de Sistematização, composta por Ada Pellegrini Grinover, Aluisio Gonçalves de Castro Mendes, Elton Venturi e Luiz Manoel Gomes Jr.

${ }^{7} \mathrm{Na}$ Câmara dos Deputados, foi registrado como Projeto de Lei 5.139/2009, sendo encaminhado para a Comissão de Constituição, Justiça e Cidadania, com tramitação conclusiva e relatoria do Deputado Antonio Carlos Biscaia. Em 18.06.2009, foi realizada audiência pública com a participação de Aluisio Gonçalves de Castro Mendes, Juiz Federal da 2. ${ }^{a}$ Região; Ricardo de Barros Leonel, Promotor Público do Estado de São Paulo; José Augusto Garcia de Souza, Defensor Público do Estado do Rio de Janeiro; Luiz Manoel Gomes Jr.,
} 
Por fim, no ano de 2019, foi constituído, pela Presidência do Conselho Nacional de Justiça (CNJ), o Grupo de Trabalho ${ }^{8}$ com o objetivo de apresentar propostas voltadas para o aprimoramento para da tutela coletiva, sob a Coordenação da Ministra Maria Isabel Diniz Gallotti Rodrigues, do Superior Tribunal de Justiça.

\section{As Class Actions dos Estados Unidos da América}

\subsection{Evolução histórica}

O direito norte-americano, como se sabe, faz parte do sistema de common law, estando, por conseguinte, bastante calcado nos precedentes judiciais, embora o direito escrito, assim como em outros países, venha assumindo paulatinamente um papel de crescente relevância.

Em termos de demanda coletiva, os primitivos escritos sobre o tema foram feitos por Joseph Story. ${ }^{9}$ O primeiro caso, West v. Randall, ocorrido em 1820 , na verdade, passou a ser considerado não pelo seu conteúdo ou julgado, mas, sim, por ter inspirado no autor o interesse pelo tema, na medida em que o fez refletir e tecer comentários em torno da group litigation. Na espécie, um morador de Massachusetts ajuizou uma ação alegando que o seu patrimônio teria sido dilapidado pelo réu, na qualidade de trustee (uma espécie de gestor de negócios). O processo estava tramitando na Justiça Federal, tendo sido firmada sua

Consultor do Ministério da Justiça; Ada Pellegrini Grinover, jurista; Elton Venturi, Procurador da República no Paraná; Otávio Brito Lopes, Procurador-Geral do Trabalho; Rodrigo Dias, Assessor Jurídico da Confederação Nacional dos Municípios; Christina Aires Correa Lima, advogada da Confederação Nacional da Indústria; e Mauro de Azevedo Menezes, da Ordem dos Advogados do Brasil. Em março de 2010, a Comissão de Constituição, Justiça e Cidadania deliberou pela constitucionalidade do projeto e, no mérito, pela rejeição, por considerar necessário maior debate na sociedade. Desta decisão, foi interposto recurso, que foi admitido, para que o projeto seja deliberado, quanto ao mérito, pelo Plenário da Câmara dos Deputados. O recurso encontra-se ainda pendente na Câmara dos Deputados.

8 Nos termos da Portaria ${ }^{\circ}$ 152, de 30 de setembro de 2019, o Grupo de Trabalho é constituído por: Maria Isabel Diniz Gallotti Rodrigues e Luiz Alberto Gurgel de Faria, Ministros do Superior Tribunal de Justiça; Henrique de Almeida Ávila e Maria Tereza Uille Gomes Conselheiros do Conselho Nacional de Justiça; Bruno Dantas Nascimento, Ministro do Tribunal de Contas da União; Aluisio Gonçalves de Castro Mendes, Desembargador Federal do Tribunal Regional Federal da 2a Região; Sérgio Seiji Shimura, Desembargador do Tribunal de Justiça de São Paulo; Richard Pae Kim, Juiz Auxiliar da Presidência do Conselho Nacional de Justiça; Rogério Marrone de Castro Sampaio, Juiz de Direito em São Paulo; Ricardo de Barros Leonel, Promotor de Justiça em São Paulo; Fredie Didier Júnior, George Abboud, Humberto Theodoro Júnior, Patrícia Miranda Pizzol, Teresa Celina Arruda Alvim e Welder Queiroz dos Santos, advogados.

9 Destacado jurista estadunidense, que integrou a Supreme Court de 1811 até 1845, ano em que veio a falecer. Escreveu, em particular, dois tratados relacionados com a equidade: Commentaries on equity jurisprudence (1836) e Commentaries on equity pleadings (1838). 
competência sob o fundamento da diversidade de jurisdição, ${ }^{10}$ embora, na realidade, seja provável que a causa, de fato, tenha sido a ausência de tribunal de equidade em Rhode Island. Story comenta que a situação poderia ter sido diferente se houvesse outras pessoas interessadas, como herdeiras, que figurassem como litisconsortes necessários. Consequentemente, o feito poderia não prosseguir na Justiça Federal, na medida em que poderia deixar de existir a diversity jurisdiction entre as partes. Mas, segundo o raciocínio desenvolvido por Story, a partir do estudo de precedentes ingleses, a presença do interesse de outras pessoas não precisaria ensejar sempre o litisconsórcio necessário: “Onde as partes são muito numerosas e a corte percebe que será quase impossível trazê-las perante o tribunal, ou onde a questão é de interesse geral em que uns poucos podem promover uma ação em benefício de todos, ou onde houver uma associação voluntária com fins públicos ou privados em que seja possível a representação dos direitos e interesses de todos que dela fazem parte; nesses e em casos análogos, a ação se demonstra não ser meramente em nome dos autores, mas de todos os outros interessados; o pedido para formação de litisconsórcio necessário deverá ser repelido e o tribunal deverá dar prosseguimento ao processo até a decisão de mérito". ${ }^{11}$

Em 1829, a Suprema Corte apreciou o caso Beatty v. Kurtz, case em que se permitiu que um grupo de luteranos demandasse um herdeiro que os estaria ameaçando de lhes retirar a posse do barracão, no qual faziam as suas pregações, e do cemitério, onde enterravam os seus mortos. O julgado, também relatado por Story, não apresentava, no entanto, maiores dificuldades sob o ponto de vista da litigação de grupo, na medida em que o próprio grupo havia escolhido quem deveria ir a juízo em nome dos demais. Da mesma forma, não se questionava a existência do interesse comum.

\footnotetext{
${ }^{10}$ Nos Estados Unidos, a competência da Justiça Federal é firmada em razão da diversity jurisdiction, ou seja, quando as partes são naturais de Estados diversos. Todavia, quando há litisconsório, faz-se necessário que nenhum dos litisconsortes possua naturalidade comum com a parte adversa, pois, do contrário, a competência será estadual.

11 Tradução de Márcio Flávio Mafra Leal, Ações coletivas: história, teoria e prática. Porto Alegre: Fabris, 1998, p. 150, do texto em inglês, transcrito em Stephen C. Yeazell, From medieval group litigation to the modern class action, cit., p. 217: "Where the parties are very numerous, and the court perceives, that it will be almost impossible to bring them all before the court; or where the question is of general interest, and a few may sue for the benefit of the whole; or where the parties form a part of a voluntary association for public or private purposes, and may be fairly supposed to represent the rights and interests of the whole; in these and analogous cases, if the bill purports to be not merely in behalf of the plaintiffs, but of all others interested, the plea of the want of the parties will be repelled, and the court will proceed to a decree".
} 
Em 1836, Joseph Story publicou a sua obra Commentaries on Equity Jurisprudence, na qual demonstrou que havia adquirido um grande conhecimento sobre as ações coletivas. No trabalho, o autor e juiz norte-americano apontou, com precisão, a importância e o papel das demandas coletivas para o Poder Judiciário e para o acesso à Justiça. Segundo Story, a group litigation objetivou, no primeiro momento, a supressão do litígio inútil e da multiplicação de demandas, ${ }^{12}$ mas, depois, passou a se colocar, muitas vezes, entre duas funções: a) a redução do número de ações propostas (e, com isso, a carga de processos sobre o Judiciário); e b) facilitar a instauração de demandas que, de outra forma, não seriam formuladas, tendo em vista que os respectivos direitos, individualmente considerados, teriam valor muito reduzido (por conseguinte, o acesso à prestação jurisdicional seria incrementado). ${ }^{13}$

Todavia, na segunda edição dos seus Commentaries on Equity Pleadings,${ }^{14}$ Story, impregnado pelo individualismo da época, passa a enfatizar o problema das pessoas interessadas, porém ausentes, como parte no processo, defendendo, no caso, a não vinculação aos efeitos da decisão proferida na group litigation, na medida em que seus direitos não poderiam ser afetados ou atingidos: "The Court can proceed to do justice between the parties before it, without disturbing the rights or injuring the interestes of the absent parties, who are equally entitled to ist protection". 15

Em 1842, a Suprema Corte norte-americana edita um conjunto de regras de equidade, dentre as quais a Equity Rule 48, que passa a ser considerada como a primeira norma escrita relacionada com a class action nos Estados Unidos:

Equity Rule 48: "Where the parties on either side are very numerous, and cannot, without manifest inconvenience and oppressive delays, in the suit, be all brought before it,

12 Como transcrito por Stephen C. Yeazell, From medieval group litigation to the modern class action, $\mathrm{p}$. 218: "Obvious ground of the jurisdiction of Courts of Equity... is to suppress useless litigation, and to prevent multiplicity of suits".

13 Nas palavras de Stephen C. Yeazell, From medieval group litigation to the modern class action, cit., p. 218: "Story here encountered a central question of modern class action theory: whether the function of the class action is to consolidate suits that would otherwise be brought (and thus to reduce the caseload of the judiciary) or to facilitate the bringing of suits that would otherwise not be brought because the individual stakes are too small (and thus to increase the accessibility of adjudication). The first alternative aims at reducing existing litigation, the second at enabling potential litigation to occur; at some level the two stand in tension".

$14 \quad$ A primeira edição data de 1838 e a segunda de 1839.

15 Stephen C. Yeazell, From medieval group litigation to the modern class action, cit., p. 219. 
the court in its discretion may dispense with making all of them parties, and may proceed in the suit, having sufficient parties before it to represent all the adverse interests of the plaintiffs and the defendants in the suit properly before it. But in such cases the decree shall be without prejudice to the rights and claims of all the absent parties". ${ }^{16}$

Como se vê, a regra da Supreme Court agasalhou o entendimento daquele que ainda compunha o tribunal, Joseph Story, ${ }^{17}$ no sentido de não permitir que os efeitos do julgado atingissem os interessados ausentes do processo, representando, assim, a própria denegação do caráter coletivo do processo, tendo em vista que apenas os presentes estariam vinculados ao decisum, não significando, assim, mudança substancial em relação ao resultado obtido com institutos processuais tradicionais, como o litisconsórcio. Ressalvar-se-ia, no entanto, a inexigibilidade do litisconsórcio necessário, quando este se tornasse manifestamente inconveniente e opressivo, diante da numerosidade, facultando-se, por conseguinte, a ação coletiva, raciocínio que remonta, em termos lógicos, ao delineado por Story em torno do case West v. Randall, conforme supramencionado.

Não obstante os textos de Story e a previsão escrita para os litígios de grupo, o número de casos, durante aquele período, continuou a ser bastante reduzido, o que fez com que Stephen C. Yeazell indicasse que a group litigation, ao longo do século XIX, na América, fosse um procedimento sem clientela. ${ }^{18}$

Mas, dentro do contexto, o caso Smith v. Swormstedt merece menção. Em julgado ocorrido em 1853, a Suprema Corte acabou deixando de lado a restrição contida na parte final da Equity Rule 48. Na espécie, pregadores itinerantes da Igreja Metodista formaram uma associação, para a qual contribuíam com uma porção do produto obtido com a venda realizada, de porta em porta, de apetrechos religiosos. O produto do fundo, que seria utilizado para o pensionamento de pregadores idosos e seus dependentes, foi confiado a

16 Quando as partes forem numerosas em um ou outro polo e não puderem, sem manifesta inconveniência e opressivos retardamentos, figurar como parte na ação, a corte, em conformidade com sua discrição, poderá dispensá-las da atuação como parte e poderá dar prosseguimento à ação, tendo partes suficientes, diante de si, para representar apropriadamente todos os interesses contrários aos dos autores e réus na ação perante a corte. Mas, em tais casos, a decisão judicial deve ser proferida sem prejuízo para os direitos e pretensões de todas as partes ausentes.

17 Este veio a falecer em 1845. Incorreta, portanto, a informação contida em Stephen C. Yeazell, From medieval group litigation to the modern class action, cit., p. 221, e Leal, p. 151, no sentido de que a Suprema Corte teria editado a Equity Rule 48 alguns anos após a morte de Story.

18 "Group litigation in nineteenth-century in America: a procedure without a constituency", From medieval group litigation to the modern class action, cit., p. 220. 
administradores situados na cidade de Cincinnati, localizada no norte dos Estados Unidos. Com o crescimento da tensão em torno da manutenção da escravatura, que acabou resultando na Guerra de Secessão, entre 1861 e 1865, houve a cisão da Igreja Metodista e os administradores do fundo recusaram-se a remeter qualquer valor para os sulistas. Por conseguinte, foi ajuizada uma ação, em nome de um representative, mas em favor de todos os pregadores do sul e em face dos administradores e dos cerca de 3.800 religiosos do norte. A ação não foi considerada apropriada pelo tribunal de primeira instância, mas a decisão foi revertida pela Supreme Court, que considerou adequada a representação em ambas as partes e se pronunciou in dicta pela vinculação dos ausentes.

Por fim, merece registro, também, o case American Steel \& Wire Co. v. Wire Drawers' \& Die Makers' Unions, julgado em 1898, em Ohio. A empresa havia empregado o padre Paulowski, que, aparentemente, também funcionava como fura-greve profissional. Por ocasião de certa paralisação, os grevistas impediram a entrada do padre na fábrica e de substitutos dos paredistas. A companhia respondeu, propondo uma ação em face dos membros do sindicato como grupo, mas requerendo a citação apenas dos líderes da greve, como representative, a fim de obter a concessão de uma injuction para barrar a interferência dos demandados em relação às atividades de Paulowski. O tribunal mencionou a falta de precedentes, mas não teve maiores dificuldades em considerar que os líderes poderiam defender os interesses dos grevistas e que os efeitos da decisão os atingiriam. Os juízes fizeram questão de afirmar que a capacidade para representar o interesse do grupo não poderia residir apenas em autorizações formais e oficiais, mas, pelo contrário, deveria ser regulada e aferida pelas cortes, em cada caso concreto, de acordo com as circunstâncias, no sentido de que alguns pudessem defender com lealdade o interesse de todos. ${ }^{19}$

Em 1912, a Suprema Corte reformulou as Equity Rules. Assim sendo, a antiga Regra

\footnotetext{
19 "From the very nature of the case, there are sufficient of the members of the unions to defend this suit, and enough to answer all practical purposes of the order and decrees that may be asked against them. The fact of numerous memberships and the necessity for proceeding against a few are stated, and the court can see that those mentioned fairly represent the whole. The fallacy of the objection made is in supposing that the required 'representative' capacity resides in some official or authorized representative quality, attaching by reason of the action of the union itself in conferring it ... It depends on the facts in each case, and the court will regulate that matter by its decree, according to circumstances, and will insist that those brought in shall fairly represent the whole, according to the nature of the relief sought and the peculiarities of the association" (Stephen C. Yeazell, From medieval group litigation to the modern class action, cit., p. 224).
} 
48 foi revogada pela Rule 38, que continuou a ser aplicada, tão somente, aos casos de equidade. Entretanto, a grande alteração foi a supressão da referência, contida na parte final da norma suplantada, aos efeitos não vinculativos em relação aos membros da classe que não estivessem presentes como parte no processo. A eliminação, contudo, não ensejou o tratamento uniforme dos tribunais em relação à questão. Pelo contrário, o dissenso e a confusão sobre o tema continuaram a reinar nas cortes americanas, ${ }^{20}$ embora alguns julgados tenham sido de grande importância para o assentamento do problema. Nesse sentido, deve ser mencionada a decisão proferida pela Suprema Corte, no caso Supreme Tribe of Ben-Hur v. Cauble, no qual todos os membros de uma organização beneficente ficaram vinculados ao pronunciamento judicial sobre o controle e a disposição dos fundos da instituição. Na oportunidade, consignou o tribunal: ${ }^{21}$ "If the decree is to be effective and conflicting judgments are to be avoided, all the class must be concluded by the decree". ${ }^{22}$

Finalmente, em 1938, surge nos Estados Unidos o primeiro Código de Processo Civil no âmbito federal. Dentre as Federal Rules of Civil Procedure encontrava-se a de n. 23, destinada a regular as chamadas class actions, que passavam a estar disponíveis para todo o direito e não apenas para os processos calcados na equidade.

A Rule 23 previa, na verdade, três categorias diversas de ações coletivas: a) as puras, verdadeiras, autênticas ou genuínas (true); b) as híbridas (hybrid); e c) as espúrias (spurious) - classificação que é atribuída ao professor J. W. Moore, que participou da redação do Código. ${ }^{23}$ A distinção, segundo consta em geral nos livros, ${ }^{24}$ propiciou certa dificuldade de interpretação e definição clara das hipóteses.

A ação de classe pura pressupõe a existência da unidade absoluta de interesse (unity of interest), ou seja, a natureza indivisível do direito ou interesse, que seria comum (joint or common) a todos os membros do grupo. Exemplos que podem ser dados, segundo a doutrina americana, são as ações por quebra de confiança, resultante do esgotamento dos bens

\footnotetext{
20 Nesse sentido: Robert H. Klonoff, Class actions and other multi-party litigation in a nutshell, p. 8.

21 Conforme transcrição feita por Jack H. Friedenthal, Mary Kay Kane e Arthur R. Miller, Civil procedure, p. 739.

22 Se o pronunciamento judicial precisa ser efetivo e julgamentos conflitantes necessitam ser evitados, toda a classe deve estar vinculada pela decisão.

23 Stephen C. Yeazell, From medieval group litigation to the modern class action, cit., p. 230.

24 Como, por exemplo, Robert H. Klonoff, Class actions and other multi-party litigation in a nutshell, cit., p. 9, Stephen C. Yeazell, From medieval group litigation to the modern class action, cit., p. 230, Jack H. Friedenthal, Mary Kay Kane e Arthur R. Miller, Civil procedure, p. 739.
} 
confiados à guarda de alguém, ajuizadas por um dos beneficiários em face do administrador $^{25}$ ou quando os sócios de uma sociedade limitada ou o marido e a mulher buscam a tutela de um bem comum. ${ }^{26}$ Considera-se, também, autêntica, quando os direitos estão subordinados (secondary) e os legitimados ordinariamente se recusam a ir a juízo para a tutela do bem, abrindo-se, assim, a oportunidade para a legitimação extraordinária. ${ }^{27}$

Nas class actions híbridas, por sua vez, os membros da classe compartilham do interesse em relação a um bem jurídico, que está sendo objeto na ação. Todavia, o direito não é único ou comum a todos. Assim sendo, há uma pluralidade de direitos que incidem, aí sim, sobre o mesmo objeto, seja ele um bem corpóreo ou determinado fundo ${ }^{28}$ Robert $\mathrm{H}$. Klonoff $^{29}$ aponta, como espécie de hybrid class action, a causa na qual acionistas pretendem se valer de seguro contra fraude, cuja indenização incidirá sobre um determinado fundo comum disponível e limitado para a cobertura de todos. O caráter coletivo encontraria semelhança, pelo menos em termos da ratio, no ordenamento brasileiro, com a execução por quantia certa contra devedor insolvente e, também, no processo de falência, guardando-se, naturalmente, as enormes diferenças, a começar pela natureza da prestação jurisdicional pretendida, que, na América, surgiria desde a atividade de conhecimento, enquanto, no Brasil, estaria limitada à realização executiva, ainda que marcada por uma etapa preliminar cognitiva, porém restrita e vinculada.

Na última categoria, spurious class action, há uma pluralidade de interesses, mas decorrentes de uma questão comum de fato ou de direito, a indicar, como apropriada, a agregação dos direitos individuais para a utilização de um remédio processual comum. Não haveria, no caso, indivisibilidade do objeto ou mesmo um bem comum relacionado com a lide, mas, tão somente, pessoas ligadas por determinadas circunstâncias, que estivessem pleiteando a mesma espécie de providência jurisdicional. A ação coletiva espúria, dessa forma, não seria uma imposição, mas um permissivo, ao contrário das demais espécies de class action. O exemplo acima mencionado para as ações espúrias poderia ser invocado,

\footnotetext{
25 Robert H. Klonoff, Class actions and other multi-party litigation in a nutshell, cit., p. 9.

Mary Kay Kane, Civil procedure in a nutshell, p. 255.

Jack H. Friedenthal, Mary Kay Kane e Arthur R. Miller, Civil procedure, cit., p. 739: “... 'secondary' in the sense that the owner of the primary right of action refused to enforce it".

28 'The 'hybrid' category recognized that the unity of interests were 'several' but all involved the same property or fund" (Robert H. Klonoff, Class actions and other multi-party litigation in a nutshell, cit., p. 9. 29 Idem, ibidem.
} 
segundo Klonoff, ${ }^{30}$ para as spurious class actions, quando não houvesse um fundo ou recurso comum, sobre o qual os demandantes teriam de repartir suas indenizações, pois, dessa forma, não haveria, a priori, qualquer interdependência entre as pretensões formuladas pelos acionistas.

Segundo a versão original da Regra 23, nas ações coletivas autênticas e híbridas, os membros das classes envolvidas estariam sob o efeito do julgado. Na espúria, todavia, não haveria vinculação de toda a classe, mas apenas dos membros que tivessem participado do processo, o que a transformava, na prática, numa espécie de litisconsórcio liberal, ${ }^{31}$ na medida em que apenas as partes, em sentido formal, litisconsortes, estariam adstritas ao julgado. Junte-se a isso que, em relação à aceitação das spurious class actions, a exigência do "pedido de um remédio comum" (common relief be sought) ensejava grandes dificuldades. Havia tribunais, por exemplo, que negavam seguimento ao processo coletivo, quando os demandantes estivessem postulando indenizações individuais; todavia, o entendimento predominante era no sentido de que apenas a espécie de providência jurisdicional deveria ser comum. Assim sendo, estaria satisfeito o requisito da common relief quando todos os membros da classe pleiteassem ressarcimentos individuais, bem como se o pedido fosse apenas a condenação de fazer ou determinadas ordens; por outro lado, não seria admitida a ação se houvesse a conjugação de pedidos de natureza diversa, como, v.g., quando alguns membros estivessem a pedir a concessão de segurança e outros a de indenizações. ${ }^{32}$

A grande dificuldade em efetuar a distinção entre as categorias ${ }^{33}$ de ações de classe, a falta de vinculação nas spurious class actions, conhecida como “one way intervention", e a

\footnotetext{
30 Idem.

31 Como bem assinalado por Jack H. Friedenthal, Mary Kay Kane e Arthur R. Miller, Civil procedure, cit., p. 739: "Unquestionably, the most controversial of these three categories was the 'spurious' class suit, which was little more than a liberal joinder device because only the named parties were bound by the court's decree". 32 Nesse sentido, Jack H. Friedenthal, Mary Kay Kane e Arthur R. Miller, Civil procedure, cit., p. 739 e 740.

33 A confusão pode ser ilustrada no caso Deckert $v$. Independence Shares Corp.: o autor, que ajuizou a ação para defender os interesses de um grupo de investidores vítimas de uma fraude, considerou-a como híbrida. $\mathrm{O}$ réu asseverou o caráter espúrio da demanda. A corte distrital considerou-a simplesmente como uma class bill. Anulando o julgado inferior, a corte regional (circuit court) de apelação caracterizou a ação como espúria. Chegando a causa na Suprema Corte, decidiu-se pelo processamento coletivo da ação, deixando, todavia, a Excelsa Corte de se pronunciar quanto à classificação relacionada com a Rule 23. Remetida, novamente, à primeira instância, o órgão judicial distrital classificou a ação, desta vez, como híbrida, e, finalmente, quando o caso foi devolvido à corte regional, para a apreciação da apelação, o tribunal declarou que a denominação não era importante. Com todas as referências sobre o caso, vide Jack H. Friedenthal, Mary Kay Kane e Arthur R. Miller, Civil procedure, cit., p. 740, n. 19.
} 
ausência de exigências relacionadas com a aferição da predominância de questões supraindividuais sobre as peculiares, bem como da superioridade e vantagem do processamento coletivo sobre o individual, ${ }^{34}$ passaram a ser os maiores problemas dos tribunais na aplicação da Rule 23, com a redação de 1938.

Como resultado do descontentamento, ${ }^{35}$ a Suprema Corte norte-americana alterou, substancialmente, em 1966, a redação da Regra 23, procurando estabelecer uma abordagem prática e funcional para as demandas coletivas. A nova emenda foi formulada com ênfase na representação adequada e leal, como pressuposto para a manutenção das ações coletivas, cujo julgamento passaria a atingir a todos que fossem considerados como membros da classe, independentemente de se o resultado fosse ou não benéfico para eles. Como se verá adiante, vários outros aspectos relacionados, como a formação de subclasses e a necessidade de notificação dos membros, foram tratados no texto subjacente.

\subsection{As class actions no direito contemporâneo ${ }^{36}$}

O texto formulado para a Regra 23, em 1966, sofreu alterações nos anos de 1987, 1998, 2003, 2007, 2009 e 2018. Em $1^{\circ}$ de agosto de 1987, entrou em vigor uma pequena modificação redacional, alterando, na alínea (c)(2), as expressões masculinas "he" e "him" para "membro". $\mathrm{Na}$ emenda aprovada em 1998, foi acrescentada a alínea (f), possibilitando, segundo a discrição da corte, a interposição imediata de recurso contra as decisões que garantam ou deneguem o procedimento de classe. No ano de 2003, houve mudança no texto das alíneas (c) e (e), bem como inserção de duas novas - (g) e (h) -, incorporando basicamente entendimentos firmados na jurisprudência em torno de regras pertinentes à aprovação de acordos, escolha de advogados e fixação de honorários. ${ }^{37}$ Em 2005, houve importante reforma legislativa, com a

34 Esta deficiência, como afirmam Jack H. Friedenthal, Mary Kay Kane e Arthur R. Miller, Civil procedure, cit., p. 740, "permitted the maintenance of class actions that were overburdened by substantial individual issues, so that there was no assurance that judicial economy would be achieved".

35 As notas do comitê consultivo esclarecem que a versão antiga foi abandonada exatamente porque a diferenciação entre ações autênticas, híbridas e espúrias "proved obscure and uncertain" e que as ações espúrias haviam se mostrado de utilidade limitada, na medida em que não conferiam direitos ou obrigações a nenhuma outra pessoa que não fosse parte ("adjudicate the rights or liabilities of any person not a party") (Robert H. Klonoff, Class actions and other multi-party litigation in a nutshell, p. 10.

36 José Rogério Cruz e Tucci escreveu trabalho precursor sobre a ação de classe norte-americana, intitulado "Class action" e mandado de segurança coletivo.

37 Nesse sentido, André Vasconcelos Roque, A experiência das “class actions” norte-americanas: um 
entrada em vigor da Class Action Fairness Act (CAFA), estatuto que incorporou modificações no Título 28 do United States Code, com aplicação nacional e tendo como propósito assegurar benefícios justos e imediatos para os membros da classe, em caso de procedência das suas pretensões; estabelecer regras relacionadas aos honorários advocatícios, com o intuito de impedir abusos; e restabelecer os parâmetros de competência, especialmente para que fossem julgados pela Justiça Federal norte-americana os casos interestaduais de importância nacional sob o preceito da diversidade de jurisdição. Em 2007, a Rule 23 passa por uma reestruturação de texto, com mudanças somente de redação, que foram implementadas na Federal Civil Procedure Rules. A emenda de 2009 alterou o prazo recursal, de 10 para 14 dias, na Regra 23 (f). Por fim, em 26 de abril de 2018 foram aprovadas as últimas alterações, que entraram em vigor no dia $1^{\circ}$ de dezembro de 2018. Como será visto de modo mais detalhado mais adiante, foram mudanças importantes, que, de certo modo complementaram as que foram realizadas em 2003 na Regra 23 e no CAFA, em 2005, com o objetivo de dar maior representatividade, transparência e efetividade para as class actions e os acordos celebrados de modo prévio ou incidental.

Para facilitar a incursão sobre o palpitante tema e o enfrentamento das questões teóricas e práticas suscitadas, far-se-á, abaixo, uma breve exposição sobre a estrutura da Regra 23, seguindo-se com a apresentação dos principais pressupostos e requisitos relacionados com as class actions e, por fim, a abordagem de algumas questões polêmicas.

Há que se registrar, ainda, que, dentro da estrutura federativa norte-americana, os Estadosmembros possuem competência para legislar sobre direito processual no âmbito da Justiça Estadual. A maioria, entretanto, segue, em termos de ações de classe, o padrão estabelecido na norma federal, sendo, portanto, seu estudo de certa forma suficiente para a compreensão do quadro nacional.

\subsubsection{A estrutura da Regra 23}

A Rule 23 estabelece, preliminarmente, de modo implícito ou expresso, pressupostos processuais e condições da ação para a admissibilidade e para o prosseguimento da defesa

ponto de reflexão para as açães coletivas no Brasil, dissertação de mestrado, Universidade do Estado do Rio de Janeiro, p. 151. 
coletiva de direitos em juízo. Cabe ao autor o ônus de demonstrar que todas as exigências se encontram satisfeitas.

A Regra 23, segundo a redação atual, encontra-se repartida em oito alíneas, de (a) até (h).

A alínea (a) fixa quatro pré-requisitos para a admissibilidade da class action. O item seguinte, (b), denominado Types of Class Actions, estabelece as espécies de ações - b(1)(A), $\mathrm{b}(1)(\mathrm{B}), \mathrm{b}(2)$ e (b)(3) - que podem ser processadas como sendo de classe, cujo enquadramento se deve fazer cumulativamente com as exigências contidas em (a).

O dispositivo (c) prescreve determinações que deverão ser tomadas no caso de prosseguimento (certificação) da ação como de classe, regulando, em particular, os atos de comunicação (notice) necessários, os efeitos da coisa julgada coletivamente e a possibilidade da condução coletiva de determinadas questões e do fracionamento do processo, mediante a formação de subclasses.

O item (d) prevê os poderes do juiz para o processamento da demanda coletiva, o que é especificamente importante, na medida em que a interferência do órgão judicial, na condução de uma class action, é muito superior e intensa, se comparada com a distância mantida nas demais causas, como decorrência do adversary sistem da common law.

A alínea (e) trata do acordo, da extinção voluntária do processo e do compromisso nas class suits. Em seguida, encontram-se sob (f) as disposições relacionadas com o cabimento de recurso contra as decisões de admissibilidade ou não das ações de classe. Na alínea (g) estão dispostas as regras pertinentes ao advogado do grupo, em termos de nomeação pelo juízo, critérios para a indicação, designação provisória e deveres funcionais. Por fim, no item (h), há normas regulando os honorários advocatícios.

\subsubsection{Pré-requisitos para a class action}

\subsubsection{A parte representativa deve integrar a classe}

O primeiro requisito, considerado implícito ou decorrente ${ }^{38}$ da parte inicial da Regra 23(a), é que haja uma classe identificável. A denominação de classe, no caso, não possui

\footnotetext{
38 Nesse sentido, Richard L. Marcus e Edward F. Sherman, Complex litigation: cases and materials on advanced civil procedure, p. 220.
} 
acepção política, econômica ou social, mas, sim, significação ampla, que pode ser equiparada a conjunto de pessoas interessadas, grupo ou categoria, não se exigindo, inclusive, qualquer relação jurídica base entre elas. Assim sendo, a definição da classe deve estar suficientemente clara e precisa, permitindo que se saiba, por conseguinte, o alcance e os limites subjetivos do julgado, embora não se exija, a priori, desde o limiar do processo, a indicação exata das pessoas ou mesmo do número certo de interessados. Importa, sim, que estejam devidamente delineados os contornos da classe, de modo tal que seja possível ao julgador, por exemplo, a partir dos elementos fornecidos, verificar se determinados indivíduos podem ou não ser considerados como membros da classe. ${ }^{39}$ A definição pode, também, ser importante para a viabilidade da comunicação (notice) aos membros, quando exigida. A existência de ambiguidades pode acarretar sérios problemas para a determinação dos limites subjetivos da coisa julgada e para a executabilidade ou cumprimento da decisão. ${ }^{40}$

\subsubsection{Numerosidade e inviabilidade do litisconsórcio}

Exige-se, em segundo lugar, conforme inscrito expressamente na Regra 23(a)(1), que a classe seja tão numerosa que a reunião de todos os membros seja impraticável ("the class is so numerous that joinder of all members is impracticable"). Chamada de "numerosity", a condição não demanda, na verdade, a demonstração da impossibilidade do ajuntamento, mas, apenas, a extrema dificuldade ou inconveniência. ${ }^{41} \mathrm{O}$ imperativo da "numerosidade" está relacionado com o escopo das ações coletivas. Estas devem representar, por um lado, uma medida de economia judicial e processual e, por outro, propiciar o acesso à prestação

\footnotetext{
39 Como mencionam Friedenthal, Kane e Miller, Civil procedure, p. 741 e 742: "It is axiomatic that before a class action should be permitted to proceed as such, an identifiable class must exist. This does not mean that every member of the represented group must be identified, or ever identifiable, at the outset of the litigation. Rather, the general contours of the class shoud be delineated sufficiently so that it would be feasible for the court to ascertain whether particular individuals are or are not members of it". Na mesma direção, é apontado por Richard L. Marcus e Edward F. Sherman, op. cit., p. 220: "It must be clear enough that the court and the parties understand who it includes, though the exact persons and even the exact number of persons".

40 Como comentado por Richard L. Marcus e Edward F. Sherman, Complex litigation, p. 220-221, embora com certa ressalva: "It is also sometimes said (although we reserve judgment as to the validity of this statement) that the class definition should be sufficiently clear and precise to show who is affected by res judicata as to the judgment in a class action".

41 Nas palavras de Robert H. Klonoff, Class actions and other multi-party litigation in a nutshell, cit., p. 20: "The numerosity standard requires only that joinder be impracticable or difficult; joinder need not be impossible".
} 
jurisdicional daqueles que, de outro modo, não lograriam receber a tutela dos seus direitos. Consequentemente, quando a defesa individual, mediante o instituto do litisconsórcio ou de outro meio, for suficiente, razoável e satisfatória, sob o ponto de vista dos jurisdicionados e dos órgãos judiciais, há que se ter como desnecessária e incabível a class action.

O requisito não se restringe ao mero número de interessados, como se poderia pensar. Inúmeros fatores podem influenciar no sentido de tornar viável a reunião dos interessados. Dentre outros, podem ser apontados, e.g., a dispersão geográfica dos membros da classe, pois, se estiverem espalhados por diversas regiões, será mais difícil, onerosa e inconveniente a reunião; o diminuto valor patrimonial da indenização ou do direito pretendido, individualmente considerado, tendo em vista que é da natureza humana confrontar os custos e benefícios para que decisões sejam tomadas, o que tornará mais improvável o ajuizamento de ações separadas, quando as pretensões representarem quantias pequenas ou irrisórias; a natureza e a complexidade das causas: determinadas lides estão relacionadas com intrincadas questões técnicas, científicas ou jurídicas, desestimulando e encarecendo o ajuizamento de ações individuais, na medida em que profissionais qualificados e estudos prévios serão necessários; ou a própria mutabilidade dos integrantes do grupo. Portanto, o aspecto quantitativo deverá ser sempre sopesado em consonância com as demais circunstâncias do caso concreto, não sendo fundamental, desse modo, a estipulação arbitrária e isolada de limites numéricos.

\subsubsection{Existência de questões comuns de fato ou de direito}

A ação só será admitida como coletiva, segundo o previsto na Rule 23(a)(2), se houver uma ou mais questões de direito ou de fato que seja(m) comum(ns) à classe. ${ }^{42}$ Não se exige, obviamente, a identidade absoluta de todas as questões apreciáveis no feito. Todavia, a "commonality", como é chamada, deve incidir sobre ponto relevante para a causa e deve ser, inclusive, conjugada e avaliada em conformidade com a exigência, contida na Rule 23(b)(3), de predominância das questões comuns e de superioridade da defesa coletiva sobre a individual. ${ }^{43}$ Jack H. Friedenthal, Mary Kay Kane e Arthur R. Miller afirmam, por exemplo,

\footnotetext{
$42 \quad$ Rule 23(a)(2): "There are questions of law or fact common to the class." 
que o requisito tem sido satisfeito quando um padrão de conduta de discriminação é alegado, a despeito de a conduta poder ter afetado de diversas maneiras vários membros da classe. ${ }^{44}$

\subsubsection{Identidade de pretensões ou defesas entre o representante e a classe}

Encontra-se na Regra 23(a)(3) a condição denominada tipicality, segundo a qual devem as pretensões ou defesas formuladas pelas partes representativas ${ }^{45}$ ser típicas das pretensões ou defesas da classe. ${ }^{46} \mathrm{O}$ significado exato e a extensão do requisito carecem de consenso absoluto. Há autores, como Robert H. Klonoff, ${ }^{47}$ que classificam em separado, como requisito implícito, a necessidade de a parte representativa integrar a classe, deixando, no caso, para o âmbito da tipicality somente a verificação da compatibilidade entre a parte representativa e a classe, em termos de pretensão ou defesa. Nos escritos de Jack H. Friedenthal, Mary Kay Kane e Arthur R. Miller, no entanto, ambas as indagações encontram-se no campo da exigência ora tratada.

A norma pressupõe que o membro da classe, por possuir um interesse pessoal e direto na lide, estará, aparentemente, apto a empreender os melhores esforços para perseguir os objetivos do grupo. O sentido teleológico do preceito é a melhor proteção dos interesses da classe, e, por conseguinte, a alegação de que a parte representativa não integra o grupo significa, corolariamente, a falta de adequada representação.

A falta de tipicidade pode ensejar a inadmissibilidade ou a subdivisão da ação de classe. No caso La Mar v. H. \& B. Novelty \& Loan Co., ${ }^{48}$ por exemplo, numa ação versando sobre

\footnotetext{
44 "For example, the requirement has been satisfied when a pattern of discriminatory conduct was alleged, despite the fact that the conduct might have affected various class members in different ways" (Civil procedure, p. 743).

45 A expressão "partes representativas", também adotada por Ada Pellegrini Grinover, no seu artigo Da class action for damages à ação de classe brasileira: os requisitos de admissibilidade, é utilizada para a tradução de representative parties. José Rogério Cruz e Tucci, em “Class action” e mandado de segurança coletivo, p. 14, preferiu, no entanto, traduzir para "litigantes", visando, talvez, evitar confusões relacionadas com os institutos da representação e da legitimação. Optou-se, entretanto, no presente trabalho, pelo uso de expressões linguisticamente mais próximas, sem prejuízo de se tentar o enfrentamento teórico da natureza, características e distinções existentes.

$46 \quad$ Rule 23(a)(3): "The claims of defenses of the representative parties are typical of the claims or defenses of the class".

$47 \quad$ Class actions and other multi-party litigation in a nutshell, p. 16, 17 e 30-36.

48489 F. 2d 461. O caso é transcrito e comentado por Richard L. Marcus e Edward F. Sherman, Complex litigation, p. 267-278.
} 
agiotagem, a Corte de Apelação do $9 .^{\circ}$ Circuito determinou a formação de subclasses, porque as partes representativas só poderiam efetuar a defesa das vítimas que tivessem sido enganadas pelo mesmo agiota.

Como posto, o requisito da tipicality ensejaria, a partir de uma interpretação mais literal, a exclusão, por tabela, da legitimidade para que associações, sindicatos, organizações não governamentais e outras entidades pudessem propor ações de classe. E, de fato, houve problemas. $^{49}$

A questão é, entretanto, mais ampla, pois no sistema tradicional de common law várias entidades (unincorporated associations), como grupos de defesa dos direitos civis, instituições religiosas, organizações não lucrativas para a proteção de interesses públicos, sindicatos etc., não possuem personalidade jurídica e judiciária, sendo-lhes vedada, consequentemente, a capacidade para ser parte nos processos judiciais. No âmbito das cortes estaduais, contudo, desde longa data, algumas legislações têm conferido a respectiva capacidade.

Data, no entanto, de 1922 decisão da Suprema Corte, proferida no caso United Mine Workers of América v. Coronado Coal Company, ${ }^{50}$ que considerou as unincorporated associations como capazes para demandar nas cortes federais, se o propósito da ação fosse o cumprimento de direito federal. Como desdobramento do julgamento, a Supreme Court estabeleceu, no corpo da Regra 17(b) ${ }^{51}$ das Federal Rules of Civil Procedure, a capacidade para que as sociedades ou associações desprovidas de personalidade jurídica pudessem demandar ou ser demandadas, segundo a legislação estadual local ou quando estivesse em questão um direito substantivo decorrente da Constituição ou das leis dos Estados Unidos (direito federal).

\footnotetext{
49 Como informam Jack H. Friedenthal, Mary Kay Kane e Arthur R. Miller, Civil procedure, cit., p. 742, n. 10: "Initially there was some problem in applying this requirement to cases in which an unincorporated association, such as a labor union, seeks to represent its member in a class suit because the association technically is not a class member if it is not seeking any remedies for itself".

$50 \quad 259$ U.S. 344 (1922).

51 "b) Capacity to Sue or be Sued. The capacity of an individual, other than one acting in a representative capacity, to sue or be sued shall be determined by the law of the individual's domicile. The capacity of a corporation to sue or be sued shall be determined by the law under which it was organized. In all other cases capacity to sue or be sued shall be determined by the law of the state in which the district court is held, except (1) that a partnership or other unincorporated association, which has no such capacity by the law of such state, may sue or be sued in its common name for the purpose of enforcing for or against it a substantive right existing under the Constitution or laws of the United States, and (2) that the capacity of a receiver appointed by a court of the United States to sue or be sued in a court of the United States is governed by Title 28, U.S.C., $\$ 754$ and 959(a)."
} 
Em termos de class actions, todavia, o tema foi, igualmente, objeto de preocupação na reforma de 1966, que acabou resultando na adoção da Regra 23.2, com a redação vigente determinada pela emenda de $2007 .{ }^{52}$ A inovação, conforme mencionado expressamente pela respectiva nota ${ }^{53}$ do Conselho Consultivo para a emenda de 1966 (Advisory Committee on 1966 Amendments to Rules), teve, de fato, como propósito principal, conferir tratamento de entidade para a associação, quando, por razões formais, não puder demandar ou ser demandada, sob a Regra 17(b), como pessoa jurídica. Junte-se a isso que, na prática, os tribunais norte-americanos já vinham permitindo a atuação das entidades, quando possuíam certa autoridade ou representação, conferida pelos membros, para a propositura de causas, em nome ou para a defesa dos seus direitos, bem como se a associação tivesse sido criada com o propósito de defender interesses que estão sendo objeto da lide.

\subsubsection{Representação adequada}

Por fim, a class action só será admitida, e mantida como tal, se as partes representativas efetuarem a justa e adequada proteção dos interesses da classe, nos termos da Rule 23(a)(4). ${ }^{54}$

O requisito encontra-se lastreado no princípio constitucional do devido processo legal. ${ }^{55}$ Mas, no caso das class actions, possui importância fundamental, pois o processo coletivo

\footnotetext{
$52 \quad$ "Rule 23.2. Actions Relating to Unincorporated Associations. This rule applies to an action brought by or against the members of an unincorporated association as a class by naming certain members as representative parties. This action may be maintained only if it appears that those parties will fairly and adequately protect the interests of the association and its members. In the conducting the action, the court may issue any appropriate orders corresponding with those in Rule 23(d), and the procedure for settlement, voluntary dismissal, or compromise must correspond with the procedure in Rule 23(e)."

53 "Although an action by or against representatives of the membership of an unincorporated association has often been viewed as a class action, the real or main purpose of this characterization has been to give 'entity treatment' to the association when for formal reasons it cannot sue or be sued as a jural person under Rule 17(b)."

$54 \quad$ Rule 23(a)(4): "The representative parties will fairly and adequately protect the interests of the class".

55 O princípio encontra-se inscrito na Emenda V, de 1791, e na Seção 1, da Emenda XIV, de 1868, da Constituição dos Estados Unidos: a) Amendment V: "No person be held to answer for a capital, or otherwise infamous crime, unless on a presentment or indictment of a Grand Jury, except in cases arising in the land or naval forces, or in the Militia, when in actual service in time of War or public danger; nor shall be compelled in any criminal case to be a witness against himself, nor be deprived of life, liberty, or property, without due process of law; nor shall private property be taken for public use, without just compensation."; b) Amendment XIV, Section 1: "All persons born or naturalized in the United States, and subject to the jurisdiction thereof, are citizens of the United States and of the State wherein they reside. No State shall make or enforce any law which shall abridge the privileges or immunities of citizens of the United States; nor shall any State deprive any person of life, liberty, or property, without due process of law; nor deny to any person within its jurisdiction the equal protection of the laws".
} 
ensejará a possibilidade de direitos e interesses individuais serem defendidos em juízo por outros titulares, sem que poderes específicos para tanto tenham sido, a priori, conferidos, voluntariamente, mediante o respectivo contrato de mandato ou outro tipo de autorização. Em decorrência, ficarão os interessados que não tenham participado do processo (absent class members) vinculados aos efeitos do pronunciamento judicial. Constitui-se, assim, hipótese de caráter excepcional, pois, dentro do sistema e do Estado Democrático de Direito, as possibilidades de representação e defesa de direitos alheios estão, em geral, associadas à manifestação de vontade do próprio titular, diretamente, como, por exemplo, através do voto, ou indiretamente, quando o representante, mediante lei, outra eleição ou substabelecimento, confere a terceiro os poderes recebidos. ${ }^{56}$

Sob outro ângulo, a regra tem, também, como escopo que sejam impedidos os conluios e acordos espúrios entre as partes representativas ou seus advogados e a parte adversa da classe.

A possibilidade de representação conferida pela lei só se justifica e se valida na medida em que for exercida devida e adequadamente. Consequentemente, estabeleceu o Estado, enquanto legislador, para os órgãos judiciais, ${ }^{57}$ o dever de fiscalizar e zelar, a todo momento, pela observância da denominada representação adequada (adequacy of representation).

$\mathrm{O}$ controle judicial deve ser exercido em relação às representative parties ${ }^{58} \mathrm{e}$ aos

\footnotetext{
56 A Suprema Corte dos Estados Unidos, ao julgar o caso Hansberry v. Lee, em 1940, teve a oportunidade de traçar o paralelo entre o princípio constitucional do devido processo legal e os limites subjetivos da coisa julgada, tendo manifestado que os limites internos podem ser excepcionalmente rompidos, nas class actions, sem prejuízo da norma prevista na Carta Magna, desde que haja, de fato, a presença de certos requisitos, dentre os quais a adequada representação: "It is a principle of general application in Anglo-American jurisprudence that on is not bound by a judgment in personam in a litigation in which he is not designated as a party or to which he has not been made a party by service of process. Pennoyer v. Neff, 95 U.S. 714 , 24 L.Ed. 565. A judgment rendered in such circumstances is not entitled to the full faith and credit which the Constitution and statute of the United States prescribes, and judicial action enforcing it against the person or property of the absent party is not that due process which the Fifth and Fourteenth Amendments require. To these general rules there is a recognized exception that, to an extent not precisely defined by judicial opinion, the judgment in a 'class' or 'representative' suit, to which some members of the class are parties, may bind members of the class or those represented who were not made parties to it. It is familiar doctrine of the federal courts that members of a class not present as parties to the litigation may be bound by the judgment where they are in fact adequately represented by parties who are present, or where they actually participate in the conduct of the litigation in which members of the class are present as parties, or where the interest of the members of the class, some of whom are present as parties, is joint, or where for any other reason the relationship between the parties present and those who are absent is such as legally to entitle the former to stand in judgment for the latter".

57 A questão deve ser apreciada pelo tribunal de primeira instância e é revista apenas nos casos de abuso de discrição, segundo Robert H. Klonoff, Class actions and other multi-party litigation in a nutshell p. 38.

58 Muitos tribunais não aceitam que a mesma pessoa funcione como parte e advogado nas class actions, como demonstram os julgados em Wagner v. Taylor, 836 F2d. 578 (D.C.Cir. 1987), Zylstra v. Safeway Stores,
} 
respectivos advogados. ${ }^{59} \mathrm{~A}$ intensidade da fiscalização leva em consideração se houve ou não autorização específica por parte dos membros da classe, bem como a autoridade que sobre estes é exercida pelas partes presentes. ${ }^{60}$

$\mathrm{Na}$ apreciação do requisito, os tribunais costumam aferir vários fatores. Mais do que a quantidade de litigantes presentes, para a certificação importa a qualidade da defesa dos interesses da classe. Em relação às partes representativas, são considerados o comprometimento com a causa, a motivação e o vigor na condução do feito, o interesse em jogo, as disponibilidades de tempo e a capacidade financeira, o conhecimento do litígio, honestidade, qualidade de caráter, credibilidade e, com especial relevo, a ausência de conflito de interesse.

No que diz respeito ao advogado, são levadas em consideração várias questões, dentre as quais a qualificação profissional, a especialização na área, a experiência com ações coletivas, a qualidade dos escritos submetidos ao tribunal e a performance na causa como um todo, o relacionamento com a parte, cumprindo com o seu dever de comunicação e esclarecimento dos membros presentes da classe, a estrutura e a capacidade do escritório para patrocinar o litígio, a conduta ética e os antecedentes, bem como a existência de conflitos de interesse.

A ausência de representação adequada poderá propiciar a decretação de invalidade ou declaração de ineficácia do julgado proferido na class action em relação ao membro ausente. ${ }^{61}$ Não por outra razão, a objeção é frequentemente levantada pela parte adversária da classe. Perfunctoriamente, pode parecer uma anomalia, mas, no fundo, o réu estará objetivando defender seus próprios interesses, seja porque o acatamento da alegação ocasionará a extinção do processo sem o julgamento do mérito, seja para garantir a efetividade da vitória, em caso de improcedência do pedido. Pois, neste caso, a representação inadequada desvincularia os membros ausentes da classe em relação à coisa julgada, que ficaria com a sua eficácia limitada às partes processuais, tal qual ocorre nas ações individuais. Logo, tornar-se-iam inócuos praticamente todos os investimentos e esforços empreendidos em razão do espectro

\footnotetext{
Inc., 578 F2ed 102 (5th Cir. 1978), e Brick v. CPC International, Inc., 547 F2d 185 (2d Cir. 1976).

59 Vide, nesse sentido, os casos Korn $v$. Franchard Corp, 456 F.2d 1206 (2d Cir. 1972), e Twyman $v$. Rockville Housing Authority, 99 F.R.D. 314 (D.Md. 1983).

60 Mason v. Garris, 360 F.Supp. 420 (N.D.Ga. 1973) e 364 F.Supp. 452 (1973), e Anderson v. City of Albany, 321 F.2d 649 (5th Cir. 1963).

$61 \quad$ Veja Gonzáles v. Cassidy, 474 F.2d 67 (5th Cir. 1973).
} 
supraindividual inicialmente delineado. ${ }^{62}$

Por outro lado, se constatada ao longo do processo, poderá ser corrigida, com a supressão do motivo ensejador da falta ou, ainda, com o reforço ou substituição dos representative parties. Para tanto, os tribunais poderão valer-se, inclusive, dos poderes conferidos especificamente na Rule 23(d), ordenando, em particular, a comunicação dos demais membros da classe, para que fiquem não apenas cientes da causa, mas para que possam se manifestar sobre a regularidade e adequação da representação, bem como para exercerem supervisão sobre o feito.

\subsubsection{As espécies de class actions}

A Regra 23(b) apresenta novas exigências, em acréscimo às anteriormente analisadas, ${ }^{63}$ para que possa haver a manutenção, ou seja, o prosseguimento do processo, da class action. Os requisitos encontram-se, todavia, divididos em três seções - b(1), b(2) e b(3) - e não são cumulativos entre si. No caso de $b(1),{ }^{64}$ o dispositivo reparte-se, ainda, em dois: $b(1)(A)$ e $b(1)(B)$.

O agrupamento das condições propicia a classificação das ações de classe, segundo as características decorrentes das exigências, como se verá a seguir, em três ou quatro espécies de class actions, conforme sejam reunidas ou afastadas as subdivisões contidas em b(1). A subsunção poderá ocorrer, eventualmente, em mais de uma regra e, por conseguinte, em mais de uma espécie de class action. Mas a certificação ${ }^{65}$ deve indicar apenas a categoria mais apropriada, levando-se em consideração que o procedimento e a sistemática, pertinentes às espécies de ações de classe, não são sempre comuns e uniformes. ${ }^{66}$

62 O elemento custo é particularmente considerado pelas partes, nas class actions, tendo em vista a repercussão quantitativa dos acordos e julgados, bem como as despesas elevadas com a produção de provas e honorários advocatícios.

63 Supra, 1.2.2.

64 "Rule 23(b): Types of Class Actions. A class action may be maintained if Rule 23(a) is satisfied and if: (1) prosecuting separate actions by or against individual class members would create a risk of: (A) inconsistent or varying adjudications with respect to individual class members would establish incompatible standards of conduct for the party opposing the class; or $(B)$ adjudications with respect to individual class members that, as a practical matter, would be dispositive of the interests of the other members not parties to the individual adjudications or would substantially impair or impede their ability to protect their interests."

65 Pronunciamento que permite a manutenção da ação como de classe, encerrando, assim, a fase prévia de admissibilidade da demanda coletiva.

66 As diferenças são, na verdade, muito grandes, e alteram substancialmente o tratamento em relação a 


\subsubsection{As ações de classe para compatibilidade de conduta - Rule 23(b)(1)(A)}

A Regra 23(b)(1)(A) estabelece que o feito será mantido como de classe se o processamento de ações separadas, por iniciativa ou em face de indivíduos membros da classe, for capaz de criar o risco de pronunciamentos judiciais inconsistentes ou variados (contraditórios), no que diz respeito aos integrantes da classe, que pudessem estabelecer padrões incompatíveis de conduta para a parte que se opõe à classe.

Como apontado por diversos autores americanos, ${ }^{67}$ o critério adotado na Rule $23(b)(1)(A)$ guarda semelhança com o esposado na exigência de litisconsórcio necessário, conforme previsto na Regra 19(a)(2)(ii). ${ }^{68}$ Porém, em razão da impossibilidade ou dificuldade de formação do litisconsórcio, com a reunião dos interessados, tendo em vista a numerosidade, coloca-se a class action como solução mais viável e econômica. ${ }^{69}$

A ação coletiva prevista na Regra 23(b)(1)(A) é chamada de "incompatible standards" class action, pois o risco de incompatibilidade no padrão de conduta, decorrente de pronunciamentos judiciais, é, na verdade, o requisito fundamental de admissibilidade. Por conseguinte, o que se pretende, normalmente, neste tipo de class action, é a determinação no sentido de que a parte contrária faça ou deixe de fazer alguma coisa (mandatory or prohibitory relief $)^{70}$ ou que haja a manutenção ou alteração do status quo.

diversas questões, como, por exemplo, à possibilidade ou não de exclusão (opt-out right) ou à obrigatoriedade de notificação dos demais membros da classe (notice).

67 Dentre outros: Richard L. Marcus e Edward F. Sherman, Complex litigation, p. 291, e Jack H. Friedenthal, Mary Kay Kane e Arthur R. Miller, Civil procedure, p. 747, n. 47.

68 "Rule 19. Joinder of Persons Needed for Just Adjudication. (a) Persons to be Joined if Feasible. A person who is subject to service of process and whose joinder will not deprive the court of jurisdiction over the subject matter of the action shall be joined as a party in the action if (1) in the person's absence complete relief cannot be accorded among those already parties, or (2) the person claims an interest relating to the subject of the action and is so situated that the disposition of the action in the person's absence may (i) as a practical matter impair or impede the person's ability to protect that interest or (ii) leave any of the persons already parties subject to a substantial risk of incurring double, multiple, or otherwise inconsistent obligations by reason of the claimed interest. If the person has not been so joined, the court shall order that the person be made a party. If the person should join as a plaintiff but refuses to do so, the person may be made a defendant, or, in a proper case, an involuntary plaintiff. If the joined party objects to venue and joinder of that party would render the venue of the action improper, that party shall be dismissed from the action."

69 Stephen C. Yeazell, From medieval group litigation to the modern class action, p. 246.

70 A distinção entre ações mandamentais e condenatórias de obrigações de fazer ou não fazer não é, no caso, relevante, na medida em que a inexistência ou existência de execução própria aparentemente não representa maiores problemas na espécie. 
Cabíveis são, portanto, na espécie, providências de natureza mandamental (ou condenatórias de fazer ou não fazer) e constitutivas. Nestas últimas, a incompatibilidade resultaria não propriamente da conduta, mas do resultado jurídico decorrente da decisão judicial, pois, como exemplificado nas notas do Comitê Consultivo da reforma de 1966, não se poderiam admitir ações singulares e, consequentemente, pronunciamentos diversos, diante de um litígio em torno da validade ou não de um empréstimo realizado pela municipalidade. Da mesma forma, se estivesse em jogo a legalidade ou invalidade de um tributo. O conflito poderia ocorrer, igualmente, em termos de demandas mandamentais, quando vizinhos pedissem determinações proibitivas em relação a determinado proprietário de terra, em razão da perturbação da paz ou da tranquilidade. Pode-se, perfeitamente, imaginar a confusão que seria se fossem propostas ações individuais, quando um juiz julgasse procedente o pedido e outro improcedente. Consequentemente, o proprietário não poderia, segundo o primeiro pronunciamento, continuar a agir como anteriormente, mas, ao mesmo tempo, estaria autorizado, pela outra decisão, a prosseguir com a conduta previamente estabelecida. Ou, ainda, a limitações inconciliáveis, como, e.g., a fixação, por cada um dos julgados, de horários diferentes de silêncio. Por conseguinte, o réu poderia ser proibido de fazer determinado barulho após as oito horas da noite e, em outro processo, apenas depois das dez.

A simples formulação de pedidos de indenizações, distintos e independentes, decorrentes de direitos individuais homogêneos, não enseja a admissibilidade das "incompatible standards" class actions. Em primeiro lugar, porque eventuais decisões diferentes poderão surgir em função de situações individuais diversas. E, por outro lado, porque, ainda que as semelhanças predominem, os pronunciamentos divergentes, versando sobre condenação de obrigação de pagar, em relação a pessoas distintas, não significam decisões conflitantes.

A “incompatible standards" class action guarda, assim, certa semelhança com a ação coletiva para a defesa dos interesses difusos ou coletivos do direito brasileiro, no que diz respeito à indivisibilidade, material ou jurídica, do direito tutelado. ${ }^{71}$

A class action da Rule 23(b)(1)(A), por buscar a tutela de interesse coletivo em sentido estrito, é considerada como cogente. ${ }^{72}$ A afirmativa, dentro da sistemática norte-americana, 
deve ser interpretada sob o ponto de vista de que a lide não poderia ser resolvida no âmbito de múltiplas ações individuais. Não fica, todavia, afastada peremptoriamente a solução tradicional do litisconsórcio necessário, por força da Regra 19, como anteriormente mencionado, que haveria de oferecer resultado uniforme para todos os litisconsortes, diante da indivisibilidade do direito. Nessa direção, deve ser lida a aparente facultatividade decorrente do texto legal - que se utiliza, no caput da seção (b), do verbo auxiliar may e não de outros como must ou have to, indicando, assim, permissibilidade. Por outro lado, a situação fática é praticamente a mesma da prevista na Rule 19, não sendo, portanto, em tese, impossível, mas, sim, desaconselhável, diante da numerosity, a incidência do litisconsórcio, em vez da ação de classe. A indispensabilidade não vem sendo apontada, da mesma forma, pela balizada doutrina, que, ao se referir à espécie, faz uso de termos - como, por exemplo, allows $^{73}$ ou permits ${ }^{74}$ - que igualmente acenam para a facultatividade relativa. Por fim, cabe mencionar, ainda, a observação contida nas notas do conselho consultivo para a elaboração da Rule 23, segundo a qual o "class action device can be used effectively to obviate the actual or virtual dilemma which would thus confront the party opposing the class".

Ajuizada, admitida e mantida, entretanto, a class action, com fulcro na Regra 23(b)(1)(A), a vinculação dos membros da classe ao decisum coletivo é absoluto. Consequentemente, não poderá qualquer interessado requerer a sua exclusão (opt-out) dos efeitos da coisa julgada.

\subsubsection{As ações de classe da Rule 23(b)(1)(B)}

A segunda categoria de ação de classe leva em consideração o risco de julgamentos, proferidos em benefício de indivíduos membros da classe, que estariam, na prática, dispondo dos interesses de outros integrantes da classe, que não são partes no processo, ou prejudicando substancialmente ou impedindo a capacidade de proteção dos seus interesses.

A Regra 23(b)(1)(B) pode ser invocada, por exemplo, se membros de uma classe estiverem perseguindo o pagamento de quantias compensatórias, que seriam subtraídas de um fundo comum limitado. Portanto, se porções do fundo forem distribuídas em ações individuais, com base na precedência dos processos, o patrimônio poderá estar completamente exaurido,

Richard L. Marcus e Edward F. Sherman, Complex litigation, p. 291.

Jack H. Friedenthal, Mary Kay Kane e Arthur R. Miller, Civil procedure, p. 747. 
retirando, assim, na prática, de parte dos membros da classe, que também detinham direitos da mesma espécie, a oportunidade de tutela dos seus respectivos interesses.

No âmbito do direito comercial, o Comitê Consultivo da reforma de 1966 previu a utilização da regra ora comentada para litígios versando sobre o direito a dividendos, pois a repartição dos lucros, no caso, deveria ser feita coletivamente e não apenas em benefício de acionistas que figurem como autores de ações individualmente propostas. É interessante notar que, na espécie, pode-se facilmente traçar um paralelo com outras hipóteses, como a distribuição de dividendos, também, em razão da liquidação de sociedade ou do rateio falimentar, respectivamente, para os sócios ou interessados e credores.

A categoria poderá ser empregada mesmo quando ausente o fundo comum limitado. Como igualmente mencionado nas notas do Advisory Committee, uma determinação judicial negativa ou positiva (negative or mandatory injuction), obtida por um dos membros da classe, pode ser capaz de impossibilitar ou afetar o cumprimento de obrigações relacionadas com outras pessoas. Assim, o pronunciamento judicial sobre os "clarances and runs" 75 de um filme, que, sob o prisma dos limites subjetivos da coisa julgada, afetaria formalmente apenas um exibidor, teria, frequentemente, efeitos práticos sobre todos os demais estabelecimentos de cinema da mesma área territorial.

Na espécie prevista sob a Regra 23(b)(1)(B), nomeada de "limited fund" class action, por alguns autores, ${ }^{76}$ também não há a possibilidade de desvinculação individual (opt-out), em razão do seu caráter obrigatório.

\subsubsection{As ações de classe da Rule 23(b)(2)}

A Regra 23(b)(2) prevê que, quando a parte adversa da classe tiver agido ou se recusado a agir, com fundamento, em geral, aplicável à classe, tornar-se-á apropriado que o remédio jurídico final, da condenação de fazer ou não fazer (injunctive relief) ou da correspondente sentença declaratória (declaratory relief), seja adotado para a classe como um todo. ${ }^{77}$

\footnotetext{
75 No contrato de exibição de filmes, é o intervalo de tempo entre a conclusão da exibição, em um cinema, e o início da apresentação em outro estabelecimento.

76 Vide Robert H. Klonoff, Class actions and other multi-party litigation in a nutshell, p. 54, e Jack H. Friedenthal, Mary Kay Kane e Arthur R. Miller, Civil procedure, p. 294.

$77 \quad$ Rule 23(b)(2): “The party opposing the class has acted or refused to act on grounds that apply generally
} 
A presente categoria não é extensível aos casos em que a pretensão definitiva está relacionada, exclusiva ou predominantemente, com a condenação pecuniária por danos, cuja persecução encontra guarida especialmente na Regra 23(b)(3), como será visto a seguir, mas, sim, para as injunções e declarações judiciais. Todavia, o simples fato de que o autor está a pedir a concessão de indenizações, além da condenação de fazer ou não fazer ou do pronunciamento declaratório, não enseja o afastamento da hipótese em comento, desde que o pedido pecuniário seja visto como incidental. ${ }^{78}$

A ação deverá ser certificada como coletiva, considerando-se tanto o ato concreto dirigido a membros da classe, que denote um padrão de atividade, quanto nos casos de a parte demandada ter estabelecido um esquema de regulamentação que afete o grupo. Não é necessário, contudo, que todos os integrantes da classe sejam diretamente afetados ou se sintam ameaçados pela conduta. ${ }^{79}$

A maioria dos processos instaurados nesta categoria refere-se a litígios relacionados com direitos civis (civil rights) ou com base em outros direitos fundamentais de natureza constitucional, embora o tipo não seja cabível apenas nestas hipóteses.

No âmbito dos civil rights, constantes são os casos de discriminação racial, religiosa e sexual. Na esfera do direito comercial e da proteção ao consumidor, v.g., a 23(b)(2) class action pode, igualmente, encontrar aplicação. Como ilustrado nas Advisory Committee Notes, compradores poderão ajuizar uma ação, em face do vendedor, diante da venda por preço superior de mercadorias que foram negociadas a valores inferiores para outros varejistas, quando o direito aplicável, por força de lei ou contrato, proíba a cotação diferenciada. Da mesma forma, se o detentor de privilégio sobre determinada máquina for acusado de vender ou licenciar a máquina, condicionando a compra ou a autorização à aquisição ou obtenção de outras licenças de máquinas acessórias não patenteadas. $\mathrm{O}$ vendedor ou cedente da licença poderia ser coletivamente demandado, tanto por consumidores ou licenciados, como por

to the class, so that final injunctive relief or corresponding declaratory relief is appropriate respecting the class as a whole".

78 Como decidido em Eubanks v. Billington, 110 F3d. 87 (DC.Cir. 1997). Vide Jack H. Friedenthal, Mary Kay Kane e Arthur R. Miller, Civil procedure, p. 749, Robert H. Klonoff, Class actions and other multi-party litigation in a nutshell, p. 65-68, e a respectiva nota do Advisory Committee.

79 Veja Advisory Committee Notes, Johson v. American Credit Co. of Georgia, 581 F2d. 526 (5th Cir. 1978), Hess v. Hughes, 500 F.Supp. 1054 (D.Md. 1980), e Jack H. Friedenthal, Mary Kay Kane e Arthur R. Miller, Civil procedure, p. 749. 
concorrentes, em razão da condição imposta (negócio casado).

1.2.3.4 A ação de classe em razão de questão comum ou indenizatória: a Rule 23(b)(3)

A ação será admitida, nos termos da Regra 23(b)(3), se a corte decidir que as questões, de direito ou de fato, comuns aos componentes da classe predominam ${ }^{80}$ em relação às que dizem respeito apenas aos membros individuais; e que a ação coletiva é superior aos demais métodos disponíveis para o julgamento justo e eficiente da controvérsia. As matérias pertinentes à decisão abrangerão: (a) o interesse dos integrantes do grupo em controlar individualmente a persecução ou defesa em ações separadas; (b) a extensão e a natureza de qualquer litígio, concernente à controvérsia, já começado por iniciativa ou em face de membros da classe; (c) a conveniência ou inconveniência em concentrar a contenda das pretensões em determinado tribunal; (d) as dificuldades que provavelmente serão enfrentadas no processamento da ação de classe. ${ }^{81}$

Assim sendo, a viabilidade da presente class action estará, básica e inicialmente, calcada sobre o binômio da "predominância", ou "prevalência", das questões comuns sobre as individuais e da "superioridade" da ação coletiva em relação às demais possibilidades processuais. $^{82}$

Como assinalado nas Advisory Committee Notes, a subdivisão (b)(3) da Regra 23 engloba casos nos quais a ação de classe possibilita a economia de tempo, de esforços e de despesas, promovendo uniformidade de decisão para pessoas situadas em situação similar, sem que haja o sacrifício da imparcialidade processual ou a produção de resultados indesejáveis.

A espécie sob comento está especialmente norteada pelos princípios do acesso à Justiça

\footnotetext{
80 Ada Pellegrini Grinover, Da class action for damages à ação de classe brasileira, p. 22 e ss., preferiu usar a expressão "prevalecem".

$81 \quad$ Rule 23(b)(3): "The court finds that the questions of law of fact common to class members predominate over any questions affecting only individual members, and that a class action is superior to other available methods for fairly and efficiently adjudicating the controversy. The matters pertinent to these findings include: (A) the class members' interests in individually controlling the prosecution or defense of separate actions; $(B)$ the extent and nature of any litigation concerning the controversy already begun by or against class members;

$(C)$ the desirability or undesirability of concentrating the litigation of the claims in the particular forum; and (D) the likely difficulties in managing a class action".

82 Nesse sentido, Ada Pellegrini Grinover, Da class action for damages à ação de classe brasileira, p. 23 e SS.
} 
e da economia processual, ${ }^{83}$ mas, na sua aplicação prática, não pode deixar de lado o incremento de valores, não menos importantes, como o do devido processo legal e do amplo direito de defesa. A apreciação dos requisitos é informada por todos esses valores e princípios.

Portanto, a economia pretendida só poderá ser efetivamente alcançada se houver a prevalência de questões comuns à classe, pois, do contrário, tornar-se-á o processo verdadeiro labirinto, diante do emaranhado de alegações, defesas e provas essencialmente individuais, ou, então, não se atendo às relevantes peculiaridades, transformar-se-á em solução, talvez célere, porém extremamente injusta.

A distinção, em termos de predominância, não deve ser feita de modo apriorístico. Como ilustrado nas Advisory Committee Notes, o ressarcimento de prejuízos decorrentes de fraudes pode ter ou não a prevalência de elementos comuns. Dentro desse ponto de vista, haverá predominância se a fraude tiver sido perpetrada em relação a várias pessoas, com o uso de ardis semelhantes, como declarações falsas, embora haja a necessidade, se houver a condenação, de se determinar, em separado, os danos sofridos pelos indivíduos da classe enganada. Por outro lado, embora possua questões comuns, um caso de fraude pode ser inadequado ao tratamento como class action, se houve variação material na representação feita ou se são de espécies ou graus diversos a relação de confiança para com as pessoas individualmente afetadas.

A aferição da superioridade é realizada sob o método comparativo, devendo o intérprete, por conseguinte, verificar a existência de outros procedimentos adequados no sistema processual norte-americano, ${ }^{84}$ bem como se seriam mais ou menos vantajosos para o caso concreto. Registre-se, contudo, que, sob o ponto de vista da uniformidade de julgamentos e da preservação do princípio da igualdade diante da lei, a common law conta, ainda, na espécie, com os préstimos do sistema de precedentes vinculativos (stare decisis).

A fixação de parâmetros e limites, para a verificação da predominância de questões comuns e da superioridade da ação coletiva, não tem sido tarefa fácil ou pacífica, na

\footnotetext{
$83 \quad$ Idem, p. 24.

84 Jack H. Friedenthal, Mary Kay Kane e Arthur R. Miller, Civil procedure, p. 750-751, mencionam exemplos que vão do estrito processamento individual até o estabelecimento de um processo modelo ou teste (test case), passando pelo "joinder of the absent class members throgh interpleader or intervention, consolidation of separate cases for common adjudication, transfer to a single court for consolidated and coordinated pretrial activities, remitting the matter to na administrative body".
} 
doutrina e nos tribunais. Evoluções e involuções chegam mesmo a ocorrer quanto a determinados temas. Preocupações e argumentos de natureza jurídica confluem, muitas vezes, com outros no âmbito econômico e político.

Com certeza, o tema mais polêmico tem sido o da admissibilidade das class actions em sede de responsabilidade civil por ato ilícito, quando um número massivo de pessoas é lesado (mass torts). As Advisory Committee Notes dispunham, de forma expressa, que um acidente de massa que resultasse em danos para numerosas pessoas não seria, normalmente, apropriado para uma class action, porque questões significativas, não apenas sobre o montante da indenização, mas, também, no que diz respeito à responsabilidade e às respectivas defesas, poderiam estar presentes, afetando os indivíduos de diversas maneiras. Nestas circunstâncias, segundo o comitê consultivo, uma ação de classe degeneraria, na prática, em julgamentos múltiplos e separados. No período compreendido entre a entrada em vigor da nova Regra 23, em 1966, e meados da década de 80, prevaleceu a orientação formulada pelo Advisory Committee, embora algumas cortes federais de primeira instância tenham, a partir do final dos anos 70, começado a admitir as chamadas mass tort class actions. As decisões permissivas foram, no entanto, cassadas. ${ }^{85}$

A partir da metade dos anos 80, inicia-se certa tendência modificativa entre influentes autores e juízes. O entendimento anterior comportou, inclusive, autocríticas, por parte de membros do Advisory Committee de 1966, como a realizada pelo Professor Charles Alan Wright: 86 "I was an ex officio member of the Advisory Committee on Civil Rules when Rule 23 was amended, which came out with an Advisory Committee Note saying that mass torts are inappropriate for class certification. I thought then that was true. I am profoundly convinced now that that is untrue. Unless we can use the class action and devices built on the class action, our judicial system is not going to be able to cope with the challenge of the mass repetitive wrong". 87

\footnotetext{
85 Vide Robert H. Klonoff, Class actions and other multi-party litigation in a nutshell, p. 218 e ss.

Richard L. Marcus e Edward F. Sherman, Complex litigation, p. 321.

Eu era um membro ex officio do Comitê Consultivo para Normas Civis quando a Regra 23 foi emendada, tendo a nova norma surgido acompanhada de uma nota do Comitê Consultivo, que dizia que delitos de massa seriam inapropriados para a certificação das ações de classe. Eu pensava que isso estava certo, mas estou profundamente convencido, agora, que está errado. A não ser que possamos utilizar a class action e os meios construídos sobre a class action, nosso sistema judicial não estará capacitado para enfrentar os desafios das ofensas repetitivas de massa.
} 
Nos tribunais, podem ser mencionados, como ilustrativos da nova posição, os casos Jenkins v. Raymark Industries, ${ }^{88}$ versando sobre danos pessoais causados pelo amianto (asbesto); In re "Agent Orange" Product Liability Litigation, ${ }^{89}$ no qual ex-combatentes no Vietnam, bem como suas esposas, pais e filhos, pediam indenizações pelos prejuízos decorrentes da exposição ao agente esfoliante, tendo o governo americano alegado que estaria imune à responsabilidade, na medida em que a arregimentação ocorrera em razão da atividade militar, o que acabou sendo uma questão comum central; Biechele v. Norfolk and Western Railway Company, por danos causados pela poluição proveniente da poeira de carvão aos habitantes de região próxima à mina; e Pruitt v. Allied Chemical Corporation, processo em que houve o desmembramento por subclasse, conforme previsto na Rule 23(c)(5), em que um conjunto de cerca de 30.000 pessoas, dentre pescadores, comerciantes, veranistas e outros, foi lesado pela descarga de material químico altamente tóxico, durante longo tempo, na Baía de Chesapeake. $^{90}$

Robert H. Klonoff aponta, no entanto, a existência de recente tendência céptica, que ganhou força nos anos 90, diante dos casos de mass tort class actions. Jack H. Friedenthal, Mary Kay Kane e Arthur R. Miller afirmam, no entanto, que há dificuldades específicas para o cumprimento do requisito da predominância, nas ações de massa em que são pedidas indenizações por vício de produto (products liability actions), ${ }^{91}$ opinião esta que é comungada, no Brasil, por Ada Pellegrini Grinover. ${ }^{92}$

A análise dos principais casos, apontados como ilustrativos da crise ou de dificuldade específica, demonstra, todavia, a preocupação da jurisprudência no sentido de manter o equilíbrio entre a busca de soluções céleres, econômicas e ampliativas do acesso à Justiça e a preservação do direito de defesa, do devido processo legal e de soluções verdadeiramente justas e harmônicas.

Há que se ressaltar que, para a certificação com base na seção (b)(3), da Regra 23, não se exige, apenas, a existência de uma questão comum, mas que esta seja prevalente e a defesa coletiva superior. A simples presença da commonality não pode afastar, por si só, a importância

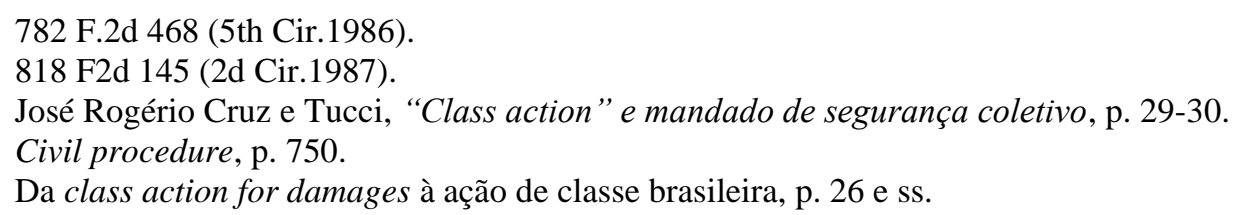


das situações e questões individuais, para se apurar, muitas vezes, a responsabilidade da parte passiva.

Nesse sentido, o julgamento de Amchem Products, Inc. v. Windson, pela Suprema Corte dos Estados Unidos, no ano de 1997, representou um marco. O caso foi certificado, na primeira instância, para fins de acordo em torno de uma ação, de âmbito nacional, visando indenizações decorrentes do produto amianto. Os juízes da Corte Suprema, entretanto, entenderam que as questões comuns, concernentes às consequências para a saúde provenientes da exposição ao asbesto, estariam excedidas em peso pelas indagações individuais postas, no que diz respeito aos membros da classe, diante da variação do nível de exposição, da diferença entre os produtos, da diversidade dos períodos de tempo em que houve contato com o amianto, bem como a variedade de danos sofridos e a existência de pessoas que não padeceram.

A repercussão do pronunciamento foi ainda maior porque não se admitiu sequer a possibilidade da celebração de eventual transação coletiva. É de se notar que, nos Estados Unidos, assim como, em geral, nos países de common law, mas, também, em outros de civil law, tal qual a Alemanha, o funcionamento do Poder Judiciário chega a estar, em grande ou na maior parte, calcado na celebração de acordos.

Nas class actions, o número chega a $90 \%$ das disputas resolvidas mediante transação. ${ }^{93}$ A falta de zelo na aferição dos requisitos para a admissibilidade e manutenção das class actions pode acabar permitindo lesão ao princípio do devido processo legal, consubstanciada em quebra da isonomia e da própria capacidade de defesa da parte adversa da classe. Enseja, dessa forma, inseguranças e incertezas suscetíveis de resultarem no incremento de acordos que, em condições normais, seriam indesejáveis ou realizados em termos bem diversos. A conduta judicial desleixada com a boa técnica facilita a propositura de ações temerárias, por vezes acusadas e qualificadas de mera chantagem judicial (judicial blackmail). ${ }^{94}$

A preocupação com as questões individuais vem sendo, por vezes, sopesada em conjunto com as consequências econômicas decorrentes do tratamento coletivo, quando estas podem ser capazes de abalar ou destruir setores produtivos inteiros, como, por exemplo, alegado e admitido, pelos tribunais, nos processos Rhone-Poulenc Rorer Inc.

\footnotetext{
93 Idem, ibidem.

$94 \quad$ Idem, p. 27.
} 


\section{v. Home Indem. Co. ${ }^{95}$ e Castano v. The American Tobacco Co. ${ }^{96}$}

O tratamento homogêneo encontra, por vezes, igualmente, razões no sistema federativo norte-americano, tendo em vista que os cinquenta Estados-membros possuem esfera significativa de atribuições, inclusive no âmbito legislativo, fazendo com que o tratamento coletivo regional ou nacional esbarre nas variações do direito (variations in State Law), tal qual, também, assinalado pelas 7. ${ }^{\text {e }}$ 5. ${ }^{\text {a }}$ Circuit Courts nos casos Rhone-Poulenc e Castano. ${ }^{97}$

Jack H. Friedenthal, Mary Kay Kane e Arthur R. Miller ${ }^{98}$ mencionam, entretanto, que, além da predominância das questões comuns e da superioridade da ação coletiva, em todas as class actions mantidas sob a subdivisão (b)(3), por força do previsto na Regra 23(c)(2)(B), o órgão judicial deverá ordenar que sejam os membros da classe notificados (notice), da melhor maneira possível dentro das circunstâncias, incluindo notificações pessoais para todos os componentes que possam ser identificados por meio de razoável esforço. A notificação deverá, de modo claro e conciso, expor em linguagem de fácil entendimento: (i) a natureza da ação; (ii) a definição da classe certificada; (iii) as pretensões, questões ou defesas da classe; (iv) que um membro da classe poderá ingressar no processo, assistido por advogado, se assim desejar; (v) que a corte excluirá da classe qualquer membro que requerer a sua exclusão; (vi) o prazo e a maneira para requerer a exclusão; (vii) o efeito vinculante em relação aos membros da classe

\footnotetext{
$95 \quad 51$ F.3d 1293 (7th Cir.1995). Pretendia-se a indenização de hemofílicos infectados pelo vírus HIV, em todo o país, por companhias farmacêuticas, que comercializavam sangue sólido manufaturado.

9684 F3d. 734 (5th Cir.1996). No caso Castano, a classe havia sido definida, inicialmente, pela corte de primeiro grau que havia certificado a class action, abrangendo todos os dependentes de nicotina dos Estados Unidos, que houvessem adquirido e fumado cigarros fabricados pelos réus, bem como os seus herdeiros, representantes e administradores, esposas, filhos, pais e outras pessoas significativas para os dependentes, como herdeiros ou sobreviventes, desde o ano de 1943.

97 Consignou expressamente o acórdão do tribunal de apelação federal que a corte de primeiro grau havia abusado da discrição, relacionando, inclusive, as variações do direito com a falta de superioridade da ação de classe: "The district court abused its discretion by ignoring variations in state law and how a trial on the alleged causes of action would be tried. Those errors annot be corrected on remand because of the novelty of the plaintiffs' claims. Accordingly, class treatment is not superior to individual adjudications. (...) The collective wisdom of individual juries is necessary before this court commits the fate of an entire industry or, indeed, the fate of a class of millions, to a single jury. For the forgoing reasons, we reverse and remand with instructions that the district court dismiss the class complaint" (apud Richard L. Marcus e Edward F. Sherman, Complex litigation, p. 336-337).

98 Civil procedure, cit., p. 749. Na nota 63, em particular, defendem a inclusão da exigência de notificação, como um dos três requisitos, embora não previsto especificamente na Regra 23 (b)(3), porque inúmeros processos têm sido extintos, sem julgamento do mérito, em razão da impossibilidade ou falta de disposição de informar os membros da classe sobre a ação, devendo, assim, segundo os autores, ser considerada como um dos requisitos para a manutenção da common question class action.
} 
de um julgamento coletivo sob a Regra 23(c)(3). ${ }^{99}$

\section{As modificações da Regra 23 em vigor a partir de Dezembro de 2018}

2.1 Comunicação dos membros da classe a partir de meios adequados

O sistema norte-americano de class actions sempre enfatizou a importância da comunicação dos interessados, ou seja, dos membros da classe. A referida comunicação, no início, estava relacionada, basicamente, à possibilidade de os integrantes da classe atingida poderem realizar o seu direito de exclusão (opt-out right) do processo coletivo. Entretanto, com as modificações empreendidas, especialmente no ano de 2003, a necessidade da notice passou a estar também diretamente relacionada com a ciência dos termos de eventual acordo proposto e a possibilidade de rejeição do acordo apresentado. Ressalte-se que, nos Estados Unidos, a maioria das demandas, cerca de noventa por cento, inclusive no âmbito dos processos coletivos, se encerra mediante o acordo entre as partes.

Contudo, o primeiro aspecto que se quer salientar da emenda, que entrou em vigor no final de 2018, diz respeito a um problema que se colocava de longa data na doutrina e nos julgados norte-americanos, ou seja, sobre como se deveria efetivar a comunicação dos membros da classe. Por um lado, a importância da comunicação no modelo norte-americano, para fins de ciência da classe, aceitação dos termos da demanda coletiva proposta, inclusive quanto à representação, para fins da não realização do opt-out, da própria certificação, e a um eventual acordo proposto, exigia que a informação fosse veiculada do melhor modo possível. Buscava-se, assim, a realização de todos os esforços para que o membro da classe fosse efetivamente cientificado e pudesse realmente escolher entre a permanência no

\footnotetext{
99 Rule $23(c)(2)(B)$ for $(b)(3)$ Classes: "For any class certified under Rule 23(b)(3)-or upon ordering notice under Rule 23(e)(1) to a class proposed to be certified for purposes of settlement under Rule 23(b)(3)-the court must direct to class members the best notice that is practicable under the circumstances, including individual notice to all members who can be identified through reasonable effort. The notice may be by one or more of the following: United States mail, electronic means, or other appropriate means. The notice must clearly and concisely state in plain, easily understood language: (i) the nature of the action; (ii) the definition of the class certified; (iii) the class claims, issues, or defenses; (iv) that a class member may enter an appearance through an attorney if the member so desires; $(v)$ that the court will exclude from the class any member who requests exclusion; (vi) the time and manner for requesting exclusion; and (vii) the binding effect of a class judgment on members under Rule 23(c)(3)".
} 
processo coletivo, com uma possível concordância com o acordo ventilado, ou o exercício do direito de exclusão. Na primeira hipótese, haveria o efeito vinculativo do membro da classe à solução consensual ou à decisão judicial proferida, conforme o caso. Na segunda, o integrante auto excluído da classe ficaria desvinculado da respectiva class action, ficando livre para participar de outra demanda coletiva, buscar a sua pretensão individualmente ou simplesmente nada fazer. Portanto, a lógica do sistema, ou seja, a existência do efeito vinculativo depende da aceitação, ainda que tácita, do membro da classe, em relação ao processo coletivo ou à solução consensual proposta. Mas, para tanto, o pressuposto era, e continua sendo, a realização e efetivação da comunicação ao integrante da classe.

O cerne da inovação de 2018, em relação à notificação, foi a introdução da previsão expressa no sentido de que a comunicação pode ser feita mediante um ou mais dos seguintes meios: correio norte-americano, comunicação eletrônica ou outro modo apropriado ${ }^{100}$, nos termos da Regra 23(c)(2)(B). A modificação pode parecer diminuta ou singela, se descolada da trajetória histórica. Entretanto, devidamente contextualizada, foi um longo e tortuoso período, desde o precedente Eisen v. Carlisle \& Jacquelin ${ }^{101}$, formado em 1974, a partir do qual a interpretação predominante nos tribunais foi no sentido de que haveria a necessidade de notificação pessoal e individual de cada integrante da classe mediante correspondência (first class mail). Este entendimento foi objeto de grande debate, considerando a limitação quanto ao modo de realizar a comunicação e, também, às dificuldades e os custos para o envio de correspondência formal e individualizada para grupos, por vezes extremamente numerosos.

A flexibilização nos meios de comunicação chegou a ser objeto de debate e de proposta formulada por ocasião da elaboração do anteprojeto de Código Brasileiro de Processos Coletivos, elaborado na UERJ-UNESA. A proposição pugnava pela ampliação da legitimação, possibilitando que o membro do grupo, categoria ou classe pudesse propor ação coletiva para a defesa dos direitos ou interesses coletivos ou individuais homogêneos, sendo

\footnotetext{
${ }^{100}$ The notice may be by one or more of the following: United States mail, electronic means, or other appropriate means.

${ }^{101}$ Eisen v. Carlisle \& Jacquelin, 417 U.S. 156 (1974).
} 
necessária 102 "a comunicação dos interessados, titulares dos direitos ou interesses individuais homogêneos objeto da ação coletiva, para que possam exercer no prazo fixado seu direito de exclusão em relação ao processo coletivo". E, no respectivo parágrafo segundo, especificava: “A comunicação prevista no caput poderá ser feita pelo correio, por oficial de justiça, por edital ou por inserção em outro meio de comunicação ou informação, como contracheque, conta, fatura, extrato bancário e outros, sem obrigatoriedade de identificação nominal dos destinatários, que poderão ser caracterizados enquanto titulares dos mencionados interesses, fazendo-se referência à ação e às partes, bem como ao pedido e à causa de pedir, observado o critério da modicidade do custo".

A preocupação com abertura de possibilidades, em termos de meios de comunicação, ficou consignada também no Projeto de Lei n. 5.139/2009, para uma nova Lei da Ação Civil Pública, nos termos do seu art. 13, seguindo-se a linha apontada no anteprojeto UERJUNESA. O caput do dispositivo determinava que, em se tratando de direitos ou interesses individuais homogêneos, haveria a comunicação dos interessados, titulares dos respectivos direito ou interesses objeto da ação coletiva, para que pudessem exercer, até a publicação da sentença, o seu direito de exclusão em relação ao processo coletivo, sem prejuízo da ampla divulgação pelos meios de comunicação social. Por sua vez, no respectivo parágrafo único, se estabelecia que a comunicação dos membros do grupo poderia ser feita pelo correio, inclusive eletrônico, por oficial de justiça ou por inserção em outro meio de comunicação ou informação, como contracheque, conta, fatura, extrato bancário e outros, sem obrigatoriedade de identificação nominal dos destinatários, que poderão ser caracterizados enquanto titulares dos mencionados direitos ou interesses, fazendo-se referência à ação, às partes, ao pedido e à causa de pedir, observado o critério da modicidade dos custo.

O novo texto da Regra 23(c)(2)(B) superou claramente a interpretação do precedente Eisen v. Carlisle \& Jacquelin, ao estabelecer expressamente não apenas a notificação pelo correio norte-americano, mas também a comunicação eletrônica, como o e-mail, e também outro modo que seja considerado apropriado pelo respectivo órgão judicial. Contudo, a regra central continua sendo a de que o Poder Judiciário deve dirigir aos membros da classe a

\footnotetext{
${ }^{102}$ Nos termos do art. 32, caput. Vide GRINOVER, Ada Pellegrini; MENDES, Aluisio Gonçalves de Castro \& WATANABE, Kazuo. Direito Processual Coletivo e o anteprojeto de Código de Processos Coletivos. São Paulo: Revista dos Tribunais, 2007, p. 443 e 444.
} 
notificação do melhor modo possível, dentro das circunstâncias ${ }^{103}$. Naturalmente, para tanto, os elementos concretos devem ser aferidos, como, por exemplo, qual a classe atingida, para se verificar se há um determinado meio de comunicação específico comum que normalmente seja veiculado junto ao grupo. Do mesmo modo, o poder aquisitivo, idade ou características do grupo, para se saber se usa ou não com regularidade a Internet ou meios eletrônicos.

Inovação relacionada com o tema da notificação, estabelecida na Regra 23(e)(1) ${ }^{104}$ foi a de que todas estas circunstâncias devem ser providas pelas partes, para que o órgão judicial possa decidir sobre o meio de notificação a ser empregado.

\subsection{Inovações pertinentes às possibilidades de soluções consensuais}

O capítulo pertinente às soluções consensuais (Rule 23(e)) foi reformulado com o claro objetivo de reforçar as normas pertinentes aos cuidados, procedimentos e necessidade de controle e aprovação pelo órgão judicial. As medidas tomadas em 2018 complementam e aprofundam as mudanças implementadas em 2003. Talvez a maior crítica às ações de classe norte-americanas estivesse relacionada com a utilização indevida deste instrumento processuais, especialmente em dois aspectos, muitas vezes relacionados entre si: a) passava a ser um meio indevido de pressão, ou chantagem (blackmail), contra empresas e corporações; b) os benefícios e resultados da demanda para os membros da classe eram aquém do devido ou insignificantes, enquanto os advogados, por vezes, recebiam proveitos desproporcionais aos destinados para o grupo interessado.

O caput da Regra 23(e) passou a estabelecer, de modo claro, que as normas contidas na referida seção "e" seriam aplicáveis tanto para as ações de classe já certificadas quanto para aquelas que ainda não haviam sido certificadas, mas em que já havia a pendência de uma proposta de acordo. Em ambas as hipóteses, haveria a necessidade de notificação, que poderia ser voltada tão somente para o acordo, quando realizada previamente a certificação, ou para a certificação e o acordo, quando ainda não certificada, com os requisitos da Regra

\footnotetext{
103 "the court must direct to class members the best notice that is practicable under the circumstances".

${ }^{104}$ Rule 23(e)(1) Notice to the Class. (A) Information That Parties Must Provide to the Court. The parties must provide the court with information sufficient to enable it to determine whether to give notice of the proposal to the class.
} 
23(c)(2)(B), possibilitando-se a manifestação do direito de exclusão por parte dos membros da classe.

Os itens da Regra 23(e) foram bastante detalhados em comparação com a versão anterior à emenda de 2018. O primeiro aspecto a ser destacado é que haverá um duplo controle judicial em relação à proposta de acordo. Portanto, haverá uma aprovação preliminar, ou seja, prévia e autorizativa da própria notificação aos membros da classe, para que possam objetar ou se excluir da proposta de acordo, bem como uma aprovação final, após o prazo para o exercício do opt-out, levando em consideração a própria quantidade ou percentual de requerimentos de exclusão, como um fator ou termômetro da aceitação da solução consensual engendrada. É interessante notar que, no direito alemão, este dado (a taxa de exclusão) passou a ser um dado objetivamente considerado pelo legislador como elemento para a aprovação ou não dos acordos estabelecidos em torno do Musterverfahren (procedimento-padrão) ${ }^{105}$.

A seção "e” da Regra 23 está subdividida em cinco partes sobre a solução consensual, respectivamente pertinentes (1) à notificação da classe; (2) à aprovação da proposta; (3) identificação de acordos relacionados com a proposta consensual; (4) à nova oportunidade de exercício do direito de auto exclusão; e (5) às objeções do membro da classe.

Em relação à notificação, as partes deverão prover o órgão judicial com a informação suficiente para que este esteja em condições de apreciar se deve ou não efetuar a notificação, pois esta somente será realizada se esta efetuar, como dito acima, um juízo preliminar que considere minimamente aceitável a proposta de acordo e também quanto aos requisitos para a certificação, ainda que esta seja feita para a aprovação do acordo. Havendo este reconhecimento, o órgão judicial deverá ordenar a comunicação dos membros da classe de uma maneira razoável, levando em consideração os elementos contidos especialmente na Regra 23(c), conforme mencionado anteriormente.

O legislador estabeleceu os critérios para a aprovação da proposta de acordo na Regra 23(c)(2), caso este seja vinculativo para os membros da classe. Os parâmetros serão levados em conta tanto na aprovação preliminar quanto na final. Contudo, a aprovação definitiva somente será realizada após audiência e quando o órgão judicial considerar que a proposição

\footnotetext{
${ }^{105}$ Nesse sentido, MENDES, Aluisio Gonçalves de Castro. Incidente de resolução de demandas repetitivas: sistematização, análise e interpretação do novo instituto processual. Rio de Janeiro: Forense, 2017, p. 50.
} 
é justa, razoável adequada, bem como que: (A) as partes e os advogados, que atuam em nome da classe, representaram adequadamente o grupo; (B) a proposta foi negociada com correção e sem qualquer conflito de interesse ${ }^{106}$; (C) que o benefício obtido para a classe é adequado; e (D) que a proposta efetua um tratamento equitativo em relação a cada um dos membros da classe. Para que o benefício seja considerado adequado (C), o órgão judicial deverá levar em consideração os seguintes elementos: (i) os custos, os riscos e a demora para o procedimento de julgamento e de recurso; (ii) a efetividade do método proposto para a distribuição do benefício para a classe, incluindo as respectivas demandas da cada membro da classe; (iii) os termos propostos para a concessão dos honorários advocatícios, incluindo o tempo para o pagamento; e (iv) outros acordos que possam ser conexos ao proposto.

O novo regramento das ações de classe preocupou-se, também, de modo mais detalhado do que na redação anterior, com as objeções dos membros da classe em relação à proposta de acordo. Exigiu-se, com a emenda de 2018, que a objeção indique se a mesma é pertinente apenas ao próprio objetor, a uma parte ou a toda a classe, apresentando a devida fundamentação. Se por um lado, o direito e a possibilidade de oferecimento de objeção pelos membros da classe foram assegurados. Por outro, já havia a preocupação, também, ainda que implicitamente, quanto a eventuais propósitos escusos na objeção. Isso se manifestava, na versão anterior, na exigência de aprovação, pelo órgão judicial, da retirada de qualquer objeção lançada. Na emenda de 2018, houve aprimoramento do controle, não se exigindo que a retirada da objeção somente fosse possível com a aprovação judicial. A redação atual estabeleceu a proibição quanto a qualquer pagamento, recompensa ou vantagem que possa ter conexão com a retirada ou renúncia de uma objeção ou de qualquer desistência, renúncia ou abandono de recurso contra a aprovação de uma proposta de acordo.

\subsection{Recursos}

As mudanças legislativas pertinentes aos recursos, contidas na Regra 23(f) não foram significativas e, também, possuem relevância para o estudo comparativo que aqui se

\footnotetext{
${ }^{106}$ A norma utiliza-se da expressão "arm's length", que significa a ausência de conflito de interesses, ou seja, que cada representante possua o devido distanciamento da parte contrária e possa realizar as negociações com a devida lisura em prol da classe para a qual atua.
} 
apresenta, razão pela qual serão sucintamente enunciadas. Em síntese, a emenda de 2018 procurou deixar claro que não seria recorrível a aprovação preliminar de uma proposta de acordo, ainda que este provimento leve em consideração a probabilidade de certificação da class action. Sendo assim, o recurso somente será cabível contra a decisão definitiva de certificação. A outra modificação foi quanto ao prazo maior, de 45 dias ${ }^{107}$, quando parte, na relação processual, os Estados Unidos, uma agência federal ou um oficial ou empregado dos Estados Unidos (quando demandado por um ato ou omissão ocorrida em conexão com os deveres cumpridos em nome do Estado norte-americano).

\section{Notas Conclusivas}

O presente texto procurou realizar uma incursão sucinta do modelo norte-americano de ações coletivas, a partir da sua evolução histórica, a configuração contemporânea e as últimas modificações que entraram em vigor em dezembro de 2018. O sistema estadunidense das class actions, por certo, é o que tem tido maior projeção histórica e atual no âmbito do Direito Processual Coletivo mundial. É referência internacional e, ainda que indiretamente, influenciou, em parte, a construção e o estudo dos instrumentos processuais coletivos no direito brasileiro. O seu estudo deve ser levado em consideração não apenas sob o prisma histórico, mas também como eventual parâmetro para as reflexões voltadas para o aprimoramento dos institutos voltados para solução de conflitos coletivos na realidade brasileira dos dias atuais. Nesse sentido, as inovações realizadas na Regra 23 das Federal Civil Procedure Rules, especialmente nos anos de 2003 e 2018, foram muito importantes para a evolução das class actions norte-americanas. Por isso, devem ser melhor conhecidas e analisadas pelos estudiosos da tutela coletiva no Brasil.

De certo modo, há um fio condutor entre o presente trabalho e o que foi escrito, dez anos atrás, para a obra comemorativa dos 25 anos da Lei da Ação Civil Pública, nesta série histórica coordenada por Édis Milaré. Naquela ocasião, este autor teve a ousadia de escrever sobre os desafios e perspectivas após 25 anos de vigência da Lei 7.347/1985. As observações e sugestões pugnadas no referido texto parecem estar ainda na ordem do dia, ainda que

${ }^{107} \mathrm{O}$ prazo normal é de 14 dias corridos. 
ultrapassados dez anos. O Direito Processual deve buscar, de modo amplo, oferecer instrumentos para que a prestação jurisdicional funcione melhor e a contento das necessidades contemporâneas da sociedade. Nesse sentido, as relações jurídicas de massa, os conflitos em escala ou com base em situação fática ou jurídica semelhante, as questões comuns controversas e os recursos repetitivos demonstram a necessidade da existência e do fortalecimento dos meios coletivos de resolução de questões e de conflitos. Para tanto, há que se ampliar o arsenal de possibilidades, oferecendo-se um verdadeiro sistema multiportas para que se possa utilizar de ferramentas adequadas para cada situação. Portanto, mecanismos como as ações coletivas estarão provavelmente convivendo com novas ferramentas, como o Incidente de Resolução de Demandas Repetitivas (IRDR) e os recursos repetitivos.

Por outro lado, as ações coletivas, estruturadas principalmente a partir da Lei da Ação Civil Pública (LACP) e do Código de Defesa do Consumidor (CDC) precisam continuar o seu processo de evolução, reflexão e aprimoramento, a partir da comparação com o direito de outros países, e eventual utilização de bons modelos e boas práticas, e da própria criatividade nacional, também oxigenada por uma nova realidade, a partir do Código de Processo Civil de 2015 e do fortalecimento de um sistema de precedentes.

Nesse contexto, o direito norte-americano oferece boas possibilidades, em termos de objetividade, de resultados e de aprimoramento no âmbito das ações coletivas, que merecem ser analisadas e talvez somadas à experiência brasileira.

Em síntese, algumas perspectivas podem ser pensadas e ficam como sugestão: $i$ ) ampliação da legitimação, com a inclusão do membro da classe; $i$ ) possibilidade de fixação do regime de inclusão (opt-in) ou de exclusão (opt-out), a ser estabelecido pelo órgão judicial (ope judicis), conforme a conveniência para o caso concreto, sendo o de exclusão como regra geral; iii) necessidade de notificação dos interessados (membros da classe), para que possam realizar o requerimento de exclusão ou de inclusão, conforme o caso; $i v$ ) controle da representatividade adequada; v) necessidade de certificação da ação coletiva, quando ajuizada pelo membro da classe; vi) coisa julgada pro et contra, como meio de se prestigiar o bom direito e se garantir a isonomia entre as partes; e vii) fortalecimento das soluções consensuais, com a possibilidade de acordo, sujeito ao requerimento de exclusão e 
homologação judicial, considerando especialmente as inovações recentes do direito norteamericano.

\section{REFERÊNCIAS}

FREIEDENTHAL, Jack H.; KANE, Mary Kay; MILLER, Arthur. Civil Procedure. 3.ed. St. Paul: West, 1999.

GIDI, Antônio. Coisa julgada e litispendência em ações coletivas. São Paulo: Saraiva, 1995.

GRINOVER, Ada Pellegrini. Da class action for damage à ação de classe brasileira: os requisitos de admissibilidade. In: Milaré, Edis. Ação civil pública: Lei 7.347/1985 15 anos. São Paulo: RT, 2001.

; MENDES, Aluisio Gonçalves de Castro; WATANABE, Kazuo. Direito Processual Coletivo e o anteprojeto de Código Brasileiro de Processos Coletivos. São Paulo: Revista dos Tribunais, 2007.

KLONOFF, Robert H. Class actions and other multi-party litigation in a nutshell. St. Paul: West, 1999.

LEAL, Márcio Flávio Mafra. Ações coletivas: história, teoria e prática. Porto Alegre: Fabris, 1998.

MARCUS, Richard L.; SHERMAN, Edward F. Complex litigation: cases and materials on advanced civil procedure. 3.ed. St. Paul: West, 1998.

MENDES, Aluisio Gonçalves de Castro. Ações coletivas e meios de resolução coletiva de conflitos no direito comparado e nacional. $4^{\mathrm{a}}$. ed. São Paulo: Revista dos Tribunais, 2014.

Incidente de resolução de demandas repetitivas: sistematização, análise e interpretação do novo instituto processual. Rio de Janeiro: Forense, 2017.

. Processos coletivos na Ibero-América. In: LUCON, Paulo Henrique dos Santos et alii. Processo em Jornadas: XI Jornadas Brasileiras de Direito Processual e XXV Jornadas Ibero-americanas de Direito Processual. Salvador: JusPodivm, 2016.

ROQUE, André Vasconcelos. A experiência das “class actions” norte-americanas: um ponto de reflexão para as ações coletivas no Brasil. Dissertação de Mestrado, Universidade do Estado do Rio de Janeiro, 2008. 
Revista Eletrônica de Direito Processual - REDP

Rio de Janeiro. Ano 15. Volume 22. Número 1. Janeiro a Abril de 2021

Periódico Quadrimestral da Pós-Graduação Stricto Sensu em Direito Processual da UERJ

Patrono: José Carlos Barbosa Moreira (in mem.). ISSN 1982-7636. pp. 781-824

www.redp.uerj.br

TUCCI, José Rogério Cruz e. “Class action” e mandado de segurança coletivo. São Paulo: Saraiva, 1990.

YEAZELL, Stephen C. From medieval group litigation to the modern class actio. New Haven: Yale University Press, 1987. 